Chapman University

Chapman University Digital Commons

ESI Working Papers

Economic Science Institute

$12-7-2017$

\title{
New Hampshire Effect: Behavior in Sequential and Simultaneous Multi-Battle Contests
}

\author{
Shakun D. Mago \\ University of Richmond \\ Roman M. Sheremeta \\ Chapman University
}

Follow this and additional works at: https://digitalcommons.chapman.edu/esi_working_papers

Part of the Econometrics Commons, Economic Theory Commons, and the Other Economics Commons

\section{Recommended Citation}

Mago, S. D., \& Sheremeta, R. M. (2017). New Hampshire effect: Behavior in sequential and simultaneous multi-battle contests. ESI Working Paper 17-25. Retrieved from https://digitalcommons.chapman.edu/esi_working_papers/240

This Article is brought to you for free and open access by the Economic Science Institute at Chapman University Digital Commons. It has been accepted for inclusion in ESI Working Papers by an authorized administrator of Chapman University Digital Commons. For more information, please contact laughtin@chapman.edu. 


\title{
New Hampshire Effect: Behavior in Sequential and Simultaneous Multi- Battle Contests
}

\author{
Comments \\ Working Paper 17-25
}




\title{
New Hampshire Effect: Behavior in Sequential and Simultaneous Multi-Battle Contests
}

\author{
Shakun D. Mago ${ }^{\text {a }}$ \\ Roman M. Sheremeta b,c,* \\ ${ }^{a}$ Department of Economics, Robins School of Business, University of Richmond, \\ 1 Gateway Road, Richmond, VA 23173, USA \\ b Weatherhead School of Management, Case Western Reserve University, \\ 11119 Bellflower Road, Cleveland, OH 44106, USA \\ ${ }^{\mathrm{c}}$ Economic Science Institute, Chapman University \\ One University Drive, Orange, CA 92866
}

December 7, 2017

\begin{abstract}
Sequential multi-battle contests are predicted to induce lower expenditure than simultaneous contests. This prediction is a result of a "New Hampshire Effect" - a strategic advantage created by the winner of the first battle. Although our laboratory study provides evidence for the New Hampshire Effect, we find that sequential contests generate significantly higher (not lower) expenditure than simultaneous contests. This is mainly because in sequential contests, there is significant over-expenditure in all battles. We suggest sunk cost fallacy and utility of winning as two complementary explanations for this behavior and provide supporting evidence.
\end{abstract}

JEL Classifications: C72, C73, C91, D72

Keywords: election, sequential contests, simultaneous contests, experiments

* Corresponding author: Roman Sheremeta, rshereme@gmail.com

We thank David Cooper, the Editor of this journal, and two anonymous referees for their valuable suggestions. We have benefitted from the helpful comments of Tim Cason, Sera Linardi, Vai-Lam Mui, Andrew Healy, James Konow, Rebecca Morton, Tim Shields, Stergios Skaperdas, Jonathan Wight, seminar participants at Loyola Marymount University, University of California Irvine, University of Richmond and participants at the International Economic Science Association Conference in Copenhagen, the Virginia Association for Economists Meeting, and the Pittsburgh Behavioral Models of Politics Conference for helpful comments. University of Richmond provided funds for conducting the experiments. The usual disclaimers apply. 


\section{Introduction}

The nomination process for the U.S. presidential election consists of a series of nationwide primary elections, beginning with the New Hampshire primary. The significance of this small New England state became entrenched in the quadrennial election politics in 1952, when Estes Kefauver defeated the incumbent President Harry Truman in the primary, leading Truman to abandon his campaign. In 1988, all but one of George Bush’s Republican opponents withdrew soon after the primary, and in 1992, number of Democratic Party candidates dwindled from five to two after the primary (Busch and Mayer, 2004). ${ }^{1}$ Controlling for other factors, Mayer (2004) finds that a win in the New Hampshire primary increases a candidate's expected share of total primary votes by a

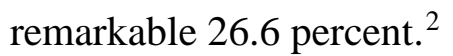

The perception that New Hampshire plays a pivotal and perhaps a disproportionately large role in the presidential election (and thereby derives a wide array of political and economic benefits from that position) led many states to move up the date of their primaries. ${ }^{3}$ 'Frontloading' is the name given to a recent trend in the presidential nomination process in which more and more states schedule their primaries near the beginning of the delegate selection process. Clustering of primaries took a huge leap forward in 1988 with the formation of 'Super Tuesday' when 16 states held their primaries on a single day in March. By 2008, 24 states held their primary on Super

\footnotetext{
${ }^{1}$ Just as candidates who do poorly in the New Hampshire primary frequently drop out, the lesser-known, underfunded candidates who do well in the primary suddenly become serious contenders to win the party nomination, garnering tremendous momentum both in terms of media coverage and campaign funding. In 1992, Bill Clinton, a little known governor of Arkansas did surprising well, and was labeled the "Comeback Kid” by the national media. In 2000, John McCain emerged as George Bush’s principal challenger only after an upset victory in New Hampshire, and a similar comeback was made by John Kerry in the 2004 primary.

${ }^{2}$ In a multi-candidate race, even a second-place finish in New Hampshire primary increases a candidate's final vote by 17.2 percent (Mayer, 2004).

3 The total economic impact of 2000 primary on New Hampshire’s economy was estimated to be \$264 million. The state also receives a diverse array of 'special policy concessions' as a result of its privileged position in the presidential nomination process (Busch and Mayer, 2004). Originally held in March, the date of the New Hampshire primary has been moved up repeatedly to maintain its status as first (a tradition since 1920). In fact, the state law requires that its primary must be the first in the nation.
} 
Tuesday held in the first week of February. In 2004, James Roosevelt, co-chair of the Democratic Party Rules Committee proclaimed: "We are moving towards a de facto national primary."

For obvious reasons, with naturally-occurring data, it is difficult to examine the exact impact of the two alternative electoral structures on both election outcomes and their economic efficiency. For this reason, we use a controlled laboratory experiment to compare a sequential contest, such as the current presidential primaries, to a simultaneous contest, as reflected in a counterfactual national primary. ${ }^{4}$ Our theoretical framework is based on Klumpp and Polborn (2006). In this political contest model, candidates have to win the majority of electoral districts in order to obtain a prize - the party nomination. As in Tullock (1980) and Snyder (1989), candidates can influence the probability of winning an electoral district by their choice of campaign expenditure in that district. In case of a sequential contest, theory predicts that candidates should spend disproportionately larger amounts in the earlier districts than in the later districts. This difference in expenditure is attributed to the "New Hampshire Effect." That is, the outcome of the first election creates asymmetry between ex-ante symmetric candidates in terms of their incentive to spend resources in the next district, which in turn, endogenously increases the probability that the winner of the first district will win in subsequent districts and attain the final prize. For example, in a sequential contest with three districts (battles), the winner of the first battle wins the overall contest with probability of 0.875 . Furthermore, the intense concentration of expenditure in the initial battles entails that there is a 0.75 probability that the contest will end in only two battles. In contrast, in case of a simultaneous contest, candidates are predicted to spend equal amounts of

\footnotetext{
${ }^{4}$ Our experiment compares two extreme benchmarks: a completely sequential contest to a completely simultaneous contest. Present day primary system, however, has a mixed temporal structure. The nomination process starts with a series of sequential elections held in various states (Iowa caucus, New Hampshire primary, etc.) followed by days such as "Super Tuesday." Klumpp and Polborn (2006) state that the results of a completely sequential contest can apply to a mixed temporal contest, as long as the latter begins with at least a few sequential battles.
} 
resources in all three battles. An important consequence of this temporal difference in contest design is that the sequential contest is predicted to induce lower expenditure than the simultaneous contest, which potentially could explain why political parties may choose the sequential electoral structure of the primaries in order to minimize wasteful campaign expenditure. ${ }^{5}$

Our laboratory study of the three-battle contests provides evidence for the New Hampshire Effect. We find that the strategic advantage created by the winner of the first battle makes it more likely for him to win the entire contest. However, contrary to the theoretical predictions, we find that sequential contests generate significantly higher (not lower) expenditure than simultaneous contests. This is mainly because in sequential contests, there is significant over-expenditure in all three battles. We suggest sunk cost fallacy and utility of winning as two complementary explanations for this behavior and provide supporting evidence.

Analogies between our laboratory environment and the naturally-occurring political contests are imperfect. Our design choices were made to facilitate analytical tractability and sharp experimental investigation, and do not capture all the details of the real-world elections. For instance, we assume that both contestants are symmetric and do not account for factors such as name recognition, time of announcing candidacy, information aggregation, or the nature of campaigns. We also ignore the carryover effect of winning (Schmitt et al., 2004), bandwagon effect

\footnotetext{
${ }^{5}$ The contest model is complementary to the voters' participation model (Morton and Williams, 1999; Battaglini et al., 2007). In the voters' participation model the probability of winning an electoral district by a candidate depends on the number of votes received, while in the contest model such a probability depends on the relative campaign expenditure by each candidate in that district. The complementarity between the two models arises because one of the reasons for the New Hampshire Effect that is commonly discussed in political science is information aggregation, which is implicit in voting models. For instance, Morton and Williams (1999) compare sequential and simultaneous voting and find that in sequential voting later voters use early outcomes to infer information about asymmetric candidates, and thus make better informed choices that reflect their true preferences. Battaglini et al. (2007) find that sequential voting aggregates information better than simultaneous voting and is more efficient in some information environments, but sequential voting is inequitable because early voters bear more participation costs. By assuming that both candidates are symmetric and by abstracting from costly voter participation decision, we are able to isolate how candidates' relative expenditure alone determines the likelihood of winning current and future electoral districts. That is, we examine the New Hampshire Effect resulting solely from candidates' campaign expenditure decisions.
} 
(Callander, 2007) and the conditional promise of additional funding upon winning the primary (Feigenbaum and Shelton, 2013). However, at least some of these factors do not detract from our findings. For instance, theory predicts that the New Hampshire Effect holds even if players are asymmetric in the sense that one is a better campaigner or has assured win in certain districts (Klumpp and Polborn, 2006). In fact, the exogenous ex-ante asymmetry is further strengthened in sequential contests by the endogenous ex-post asymmetry. Similarly, bandwagon theory and carryover effect provide additional rationale for momentum to shift forward to earlier battles, thereby reinforcing our results. Finally, sequential and simultaneous contests are not just restricted to political contests, and can in fact be employed to study resource allocation problems in military and systems defense (Clark and Konrad, 2007), research and development portfolio selection (Clark and Konrad, 2008), and advertising (Friedman, 1958). By contrasting sequential and simultaneous multi-battle contests in the simplest possible framework using laboratory data, which is untainted from the various complicating factors that plague naturally-occurring data, we provide a direct empirical test of the theoretical model of primary elections by Klumpp and Polborn (2006).

The rest of the paper is organized as follows. In Section 2, we provide a brief review of the multi-battle contest literature, both theoretical and experimental. Section 3 presents our theoretical framework and Section 4 describes the experimental design, procedures and hypotheses. Section 5 reports the results of our experiment and Section 6 concludes.

\section{Literature Review}

The theoretical literature on multi-battle contests originated with seminal work by Fudenberg et al. (1983) and Snyder (1989). ${ }^{6}$ Fudenberg et al. (1983) model R\&D competition as

\footnotetext{
${ }^{6}$ One could also argue that the original formulation of a Colonel Blotto game by Borel (1921) is a starting point of the multi-battle contest literature.
} 
a sequential multi-battle contest, while Snyder (1989) models political campaigning as a simultaneous multi-battle contest. ${ }^{7}$ For a comprehensive review of the theoretical literature on multi-battle contests see Kovenock and Roberson (2012). Klumpp and Polborn (2006) directly compare sequential and simultaneous multi-battle contests in a context of primary elections. They show that the sequential contest creates a strategic advantage for the winner of the first battle, the result they call a "New Hampshire Effect," thus minimizing potentially wasteful expenditure in future battles.

We conduct an experiment to test the predictions of the theoretical model by Klumpp and Polborn (2006). While most of the existing experimental studies focus on single-battle contests, recently there has been an increased interest in examining multi-battle contests (Avrahami and Kareev, 2009; Arad and Rubinstein, 2012; Chowdhury et al., 2013; Mago and Sheremeta, 2017). For a comprehensive review of this literature see Dechenaux et al. (2015). Experimental studies on simultaneous multi-battle contests have examined how asymmetry in resources (Avrahami and Kareev, 2009; Arad, 2012; Chowdhury et al., 2013), asymmetry in objectives (Kovenock et al., 2010; Duffy and Matros, 2015; Holt et al., 2016; Montero et al., 2016), and asymmetry in battles (Horta-Vallve and Llorente-Saguer, 2010; Avrahami et al., 2014) impact behavior in contests. Experimental studies on sequential multi-battle contests have examined the impact of contest structure (Deck and Sheremeta, 2012), carryover (Schmitt et al., 2004), fatigue (Ryvkin, 2011), the length of the contest (Zizzo, 2002; Deck and Sheremeta, 2016), intermediate prizes and luck (Mago et al., 2013; Gelder and Kovenock, 2017) on behavior in dynamic contests. ${ }^{8}$ Most of these

\footnotetext{
${ }^{7}$ Building on these models, subsequent papers investigated the ramification of various factors such as the sequence ordering of decisions, number of battles, asymmetry between players, effect of carryover, effect of uncertainty, the impact of discount factor and intermediate prizes (Harris and Vickers, 1985, 1987; Leininger, 1991; Baik and Lee, 2000; Szentes and Rosenthal, 2003; Roberson, 2006; Kvasov, 2007; Konrad and Kovenock, 2009).

${ }^{8}$ Related to the studies on sequential multi-battle contests are the studies examining multi-battle elimination contests (Parco et al., 2005; Amegashie et al., 2007; Sheremeta, 2010a, 2010b; Altmann et al., 2012; Höchtl et al., 2015).
} 
studies find support for the comparative statics predictions (see the review by Dechenaux et al., 2015), but often report significant over-expenditure of resources (also known as overbidding or over-dissipation) relative to the Nash equilibrium prediction (see the reviews by Sheremeta, 2013, 2015).

Our study compares sequential and simultaneous multi-battle contests. Consistent with the previous studies, we find significant over-expenditure relatively to the Nash equilibrium in both contests. Our most surprising result is the reversal of the comparative statics prediction of Klumpp and Polborn (2006) - we find that contrary to prediction, the sequential contest generates higher expenditure than the simultaneous contest. This is surprising because, as mentioned above, almost all contest experiments in the literature find strong support for the comparative statics predictions even if the precise quantitative predictions are refuted. We suggest sunk cost fallacy and utility of winning as possible explanations for this finding.

\section{Theoretical Model}

Consider two risk-neutral and equally-skilled players, $X$ and $Y$, competing in a multi-battle contest for an exogenously determined and commonly known prize $v$. There are $n$ battles in the contest. Let $x_{i}$ and $y_{i}$ denote the amount of resource expenditure by players $X$ and $Y$ in battle $i$. Following Tullock (1980), the probabilities of winning battle $i$ by players $X$ and $Y$ are defined by a "lottery" contest success functions, such that a player’s probability of winning the battle depends on his expenditure relative to the total expenditure:

$$
p_{X i}\left(x_{i}, y_{i}\right)=\frac{x_{i}}{x_{i}+y_{i}} \quad \text { and } \quad p_{Y i}\left(x_{i}, y_{i}\right)=\frac{y_{i}}{x_{i}+y_{i}}
$$

The player who wins a majority of the battles, i.e., at least $(n+1) / 2$ battles, wins the overall contest and receives the prize $v$. Therefore, the net payoff of player $X$ (similarly for player 
$Y$ ) is equal to the value of the prize if he wins (zero otherwise) minus the total expenditure he has spent during the contest:

$$
\pi_{X}= \begin{cases}v-\sum_{i=1}^{n} x_{i} & \text { if } X \text { wins the contest } \\ -\sum_{i=1}^{n} x_{i} & \text { otherwise }\end{cases}
$$

The battles in the contest can proceed in two ways: sequentially or simultaneously. We describe the theoretical predictions for both these cases with $n=3$, although all the comparative statics predictions hold for any $n \geq 3$ (Klumpp and Polborn, 2006). We chose $n=3$ to simplify the experimental environment and to facilitate greater subject comprehension.

\subsection{Sequential Multi-Battle Contest}

In the sequential multi-battle contest, players simultaneously choose expenditure levels $x_{1}$ and $y_{1}$ in battle 1 . After determining the winner of battle 1 , they move to battle 2 where they choose expenditures $x_{2}$ and $y_{2}$. Players continue to compete until one player accumulates two victories. The solution concept we consider is the subgame perfect Nash equilibrium. Using backward induction, we begin our examination with the final and decisive battle 3. Note that if one of the players has already won the previous two battles there is no need to compete in battle 3 and thus expenditures are $x_{3}^{*}=y_{3}^{*}=0$. However, if each player has won one of previous two battles then the winner of the contest is determined by the result of battle 3. In such a case, player $X$ 's expected payoff (similarly for player $Y$ ) is equal to the probability of player $X$ winning battle $3 p_{X 3}\left(x_{3}, y_{3}\right)$ times the prize valuation $v$ minus cost of expenditure $x_{3}$ :

$$
E\left(\pi_{X 3}\right)=p_{X 3}\left(x_{3}, y_{3}\right) v-x_{3}=\frac{x_{3}}{x_{3}+y_{3}} v-x_{3}
$$

In the Nash equilibrium, battle 3 expenditures are $x_{3}^{*}=y_{3}^{*}=v / 4$ and the expected payoffs are $E^{*}\left(\pi_{X 3}\right)=E^{*}\left(\pi_{Y 3}\right)=E^{*}\left(\pi_{3}\right)=v / 4$. Going backwards to battle 2, suppose player $X$ won 
battle 1 and is leading the contest. Therefore, players are necessarily asymmetric, wherein player $X$ needs to win only one more battle to win the contest, while player $Y$ needs to win two battles. In this case, players $X$ and $Y$ have the following expected payoffs:

$$
E\left(\pi_{X 2}\right)=\frac{x_{2}}{x_{2}+y_{2}} v+\frac{y_{2}}{x_{2}+y_{2}} E^{*}\left(\pi_{3}\right)-x_{2} \quad \text { and } \quad E\left(\pi_{Y 2}\right)=\frac{y_{2}}{x_{2}+y_{2}} E^{*}\left(\pi_{3}\right)-y_{2}
$$

Note that player $X$ 's value of winning battle 2 is higher than that of player $Y$. Consequently, in battle 2 player $X$ chooses higher expenditure than player $Y$, and is more likely to win the overall contest. Klumpp and Polborn (2006) call this outcome the "New Hampshire Effect" - the outcome of battle 1 has an asymmetric effect on expenditures of ex-ante symmetric players. In the Nash equilibrium, battle 2 expenditures are $x_{2}^{*}=9 v / 64$ and $y_{2}^{*}=3 v / 64$ and the expected payoffs are $E^{*}\left(\pi_{X 2}\right)=43 v / 64$ and $E^{*}\left(\pi_{Y 2}\right)=v / 64$. Finally, going back to battle 1 , the players are symmetric again. Both players need to accumulate two battle victories to win the contest. In this case, player $X$ (similarly, player $Y$ ) maximizes the following expected payoff:

$$
E\left(\pi_{X 1}\right)=\frac{x_{1}}{x_{1}+y_{1}} E^{*}\left(\pi_{X 2}\right)+\frac{y_{1}}{x_{1}+y_{1}} E^{*}\left(\pi_{Y 2}\right)-x_{1}
$$

In the Nash equilibrium of this subgame, battle 1 expenditures are $x_{1}^{*}=y_{1}^{*}=21 v / 128$ and the expected payoffs are $E^{*}\left(\pi_{X 1}\right)=E^{*}\left(\pi_{Y 1}\right)=E^{*}\left(\pi_{1}\right)=23 v / 128$. Both players have the same expenditure profile because they have the same value for winning battle 1. Aggregating across all three battles, the expected equilibrium expenditure by each player is $41 v / 128$.

\subsection{Simultaneous Multi-Battle Contest}

In the simultaneous multi-battle contest, players simultaneously choose expenditure levels $x_{i}$ and $y_{i}$ for all three battles $i=1,2,3$. Then, the winner of each individual battle is determined and the player who wins at least two battles wins the overall contest and obtains the prize. Note 
that each battle of the multi-battle contest is an 'independent' lottery contest. Therefore, player $X$ (similarly, player $Y$ ) maximizes the following expected payoff:

$$
E\left(\pi_{X}\right)=\left[\left(\begin{array}{l}
3 \\
3
\end{array}\right)\left(\frac{x}{x+y}\right)^{3}+\left(\begin{array}{l}
3 \\
2
\end{array}\right)\left(\frac{x}{x+y}\right)^{2}\left(\frac{y}{x+y}\right)\right] v-3 x=\left[\left(\frac{x}{x+y}\right)^{3}+\frac{3 x^{2} y}{(x+y)^{3}}\right] v-3 x
$$

In the unique Nash equilibrium, both players make the same expenditure in all battles, i.e., $x_{i}^{*}=y_{i}^{*}=v / 8$ for all $i{ }^{9}$ Aggregating across all three battles, the expected equilibrium expenditure by each player is $48 v / 128$.

\section{Experimental Environment}

\subsection{Experimental Design and Hypotheses}

We employ two treatments: sequential and simultaneous. In the sequential treatment two players compete in a sequential multi-battle contest, while in the simultaneous treatment two players compete in a simultaneous multi-battle contest. Table 1 summarizes the equilibrium predictions in both treatments for $v=100$ and $n=3$. These predictions motivate the following three hypotheses:

Hypothesis 1: Total expected expenditure in the sequential contest is lower compared to the simultaneous contest.

The expected total expenditure by a player in the sequential contest is 32.4, and in the simultaneous contest is 37.5 .

Hypothesis 2: In the sequential contest, the winner of battle 1 is more likely to win battle 2 and the overall contest.

\footnotetext{
${ }^{9}$ The solution to this game can be found in Friedman (1958).
} 
In the sequential contest, the outcome of battle 1 creates asymmetry between ex-ante symmetric players. This asymmetry endogenously triggers differing expenditure levels in the subsequent battles and generates momentum for the winner of battle 1, also known as the "New Hampshire Effect.” Since it is less likely for the loser of battle 1 to win the contest, the absolute level of expenditure falls sharply after the outcome of battle 1 is known. In battle 2, the winner of battle 1 exerts three times more expenditure than the loser. As a result, sequential contest ends after two battles with probability 0.75 , and the winner of battle 1 wins the overall contest with probability 0.875 .

Hypothesis 3: In the simultaneous contest, expenditures are uniformly distributed across all three battles.

Since all three battles are identical in the simultaneous contest, both players make the same expenditure of 12.5 in each battle. This is in sharp contrast to the sequential contest where expenditures are predicted to be more intensely concentrated in the first battle. ${ }^{10}$

\subsection{Experimental Procedures}

A total of 144 subjects participated in 12 sessions (12 subjects per session). All subjects were undergraduate students at Chapman University and inexperienced in this decision-making environment. ${ }^{11}$ No one participated in more than one session. The experimental sessions were run using computer software z-Tree (Fischbacher, 2007). Throughout the session, no communication between subjects was permitted, and all choices and information were transmitted via computer

\footnotetext{
${ }^{10}$ In the sequential contest, the total expected expenditure by both players in battle 1 is 32.8 ; in battle 2 is 18.8 ; and since battle 3 is likely to occur with probability 0.25 , the unconditional expected expenditure in battle 3 is 25 .

${ }^{11} 48 \%$ of our subjects identified as males and $52 \%$ as females. The average age of the participants was 19.63 and ranged between 18 and 28 . More than $60 \%$ of the subjects were sophomores or freshmen and about $70 \%$ were majoring in business and economics.
} 
terminals. At the beginning of each session, subjects received an initial endowment of $\$ 20$ to cover any potential losses.

Each experimental session corresponded to 20 periods of play in one of the two treatments. Thus, 6 sessions featured the sequential treatment and 6 sessions featured the simultaneous treatment, generating a total of 1440 observations for each treatment ( 6 sessions $\times 12$ subjects $\times$ 20 periods). Subjects were given the instructions, available in the Appendix A, at the beginning of the experiment, and these were read aloud by the experimenter. Before the start of the experiment, subjects completed a computerized multiple choice quiz to verify their understanding of the instructions. ${ }^{12}$ The experiment started only after all subjects completed the quiz and explanations were provided for any incorrect answers. In every period, subjects were randomly and anonymously placed into 6 groups with 2 players in each group. To keep the terminology neutral, in the instructions we describe the task as one of making bids in boxes and the player who wins 2 boxes gets the prize of 100 experimental francs. We gave detailed explanations and numerical examples for the mechanisms underlying the contest structures, and how winners are determined in each battle (i.e., the lottery rule). Subjects were informed that increasing their bid would increase their chance of winning; and that regardless of who wins the prize, all subjects would have to pay their bids. In the simultaneous treatment subjects were asked to make bids in three battles simultaneously. They were not allowed to bid more than 100 francs in any battle and money spent on bidding was subtracted from the initial endowment of $\$ 20 .{ }^{13}$ After subjects submitted their bids,

\footnotetext{
12 Subjects also made 15 choices in simple lotteries, similar to Holt and Laury (2002), at the beginning of the experiment. These were used to elicit their risk aversion preferences, and subjects were paid for one randomly selected choice. We did not find any interesting patterns or correlations between risk attitudes and behavior in contests. So, we omit any discussion from the article.

13100 francs is substantially higher than the highest possible equilibrium bid, but we decided not to constrain individual bidding to be consistent with the theoretical model which assumes no budget constraints. Additionally, we wanted to avoid potential unintended behavioral consequences since enforcing even non-binding budget constraints can unexpectedly affect subjects’ behavior (Price and Sheremeta, 2011; Sheremeta, 2011).
} 
the computer displayed own bids, opponent's bids, the winner of each battle, the overall winner and own final payoff. In the sequential treatment subjects made their bidding decision sequentially, either in two or three rounds (with bids not exceeding 100 francs in any round). At the end of each round, the computer displayed own bid, opponent's bid, and the winner of the battle in that round. The period ended when one of the subjects in the group won two rounds. At the end of each period, subjects were randomly re-grouped to form a new two-person group.

At the end of the experiment, 2 out of 20 periods were randomly selected for payment. ${ }^{14}$ The sum of the earnings for these 2 periods was exchanged at rate of 25 experimental francs $=$ US \$1. On average, the experimental sessions lasted for about 60 minutes, and subjects earned \$21 which was paid anonymously and in cash.

\section{Results}

\subsection{General Results}

Table 2 presents the mean expenditure and payoff in both sequential and simultaneous contests. The average total expenditure is 56.0 in the sequential contest and 40.3 in the simultaneous contest. While the observed expenditure in the simultaneous contest is not significantly different from the equilibrium predictions (40.3 versus 37.5; Wilcoxon signed-rank test, $\mathrm{p}$-value $=0.24, \mathrm{n}=6$ ), the observed expenditure in the sequential contest is significantly higher than predicted (56.0 versus 32.0; Wilcoxon signed-rank test, $\mathrm{p}$-value $=0.02, \mathrm{n}=6$ ). We also corroborate the conclusions from these conservative nonparametric tests by estimating multivariate panel regression models. ${ }^{15}$

\footnotetext{
${ }^{14}$ We chose to select only 2 periods for payment in order to avoid intra-experimental income effects (McKee, 1989). In addition, subjects were paid for their lottery choice from the risk elicitation procedure.

${ }^{15}$ We have checked the robustness of these results by estimating a mixed-effects panel model for each treatment (see Table B1 in Appendix B). We have 1440 observations for each treatment ( 6 sessions $\times 12$ subjects $\times 20$ periods). The
} 
Over-expenditure in contests is a commonly observed phenomenon (Sheremeta, 2013, 2015; Dechenaux et al., 2015), and therefore, the result that total expenditure in the simultaneous contest conforms to the theoretical predictions may seem surprising. However, as we discuss later, instead of following the equilibrium strategy of allocating their resources to all three battles, subjects use the incomplete coverage strategy by focusing their expenditure on just two battles. Expenditure in these two battles average at 16.3, which exceeds the equilibrium prediction of 12.5. Therefore, one could speculate that we would also observe over-expenditure in the simultaneous multi-battle contest if subjects did not use a non-equilibrium strategy of incomplete coverage of battles. We discuss this in more detail in Section 5.3.

The experiment lasted for 20 periods and it is relevant to examine how expenditure evolves over the length of the experiment. Figures 1 and 2 show that expenditure decreases over time in the sequential and simultaneous contests. In the sequential contest, the average total expenditure drops from 62.9 in the first half of the experiment to 49.0 in the second half. In the simultaneous contest, it drops from 42.9 in the first half to 37.8 in the second half. Panel regressions confirm that these declines are statistically significant (p-values $<0.01) .{ }^{16}$ Overall, our result that overexpenditure decreases with repetition in the direction of equilibrium play is consistent with previous experimental findings on single-battle contests (Davis and Reilly, 1998; Sheremeta and Zhang, 2010; Price and Sheremeta, 2011, 2015; Chowdhury et al., 2014; Mago et al., 2016).

\footnotetext{
dependent variable in the regression is the total expenditure and the independent variables are a constant and a period trend. The model included a mixed-effects error structure with a 3-way nested model (observations nested within a session and then within a subject) to account for the multiple decisions made by each subject and random re-matching within a session. A standard Wald test, conducted on estimates of regression models, shows that expenditure in the sequential contest is significantly higher than predicted (p-value $<0.01$ ) and for the simultaneous contest it is not different from the prediction ( $\mathrm{p}$-value $=0.60$ ). Hypothesis testing with a few clusters (sessions) can result in overrejection of the null hypothesis. To address this concern, we also conducted regressions based on Cameron et al. (2008) wild cluster approach. The results remain the same - expenditure in the sequential contest is significantly higher than predicted and for the simultaneous contest it is not different from the prediction.

${ }^{16}$ See Table B1 in Appendix B.
} 
A comparison across the two treatments informs our Hypothesis 1 that the average total expenditure is lower in the sequential contest relative to the simultaneous contest (32.0 versus 37.5). Contrary to this prediction, however, we find that the average total expenditure in the sequential contest is higher than in the simultaneous contest (56.0 versus 40.3; Wilcoxon ranksum test, $\mathrm{p}$-value $=0.01, \mathrm{n}_{1}=6, \mathrm{n}_{2}=6$ ). This is also true when we restrict our attention only to the second half of the experiment (49.0 versus 37.8; Wilcoxon rank-sum test, $\mathrm{p}$-value $=0.05, \mathrm{n}_{1}=6$, $\left.\mathrm{n}_{2}=6\right) \cdot{ }^{17}$ It is important to emphasize that the magnitude of the difference between the two treatments is quite substantial in size. The sequential contest generates almost $40 \%$ higher expenditure than the simultaneous contest, instead of the predicted $20 \%$ lower expenditure. As a result of this over-expenditure, the observed average payoff in the sequential contest is negative and lower than prediction (-6.0 versus 18.0). On the other hand, the average payoff in the simultaneous contest is positive and very close to prediction (9.6 versus 12.5 ).

Finding 1: Average total expenditure is significantly higher in the sequential contest than in the simultaneous contest (evidence against Hypothesis 1).

Next, we take a closer look at the individual battle behavior in both sequential and simultaneous contests.

\subsection{Sequential Contests}

One of our central predictions is that the sequential contest generates the New Hampshire Effect, so that the winner of battle 1 is more likely to win battle 2 and the overall contest (Hypothesis 2). For our parameters, the winner of battle 1 is predicted to win the overall contest

\footnotetext{
${ }^{17}$ Mixed-effects panel regressions collaborate the results of the non-parametric statistical tests (see Table B2 in Appendix B). In estimating these regressions, we used total expenditure as the dependent variable and a treatment dummy-variable, a period trend, and a constant as the independent variables. Regressions based on Cameron et al. (2008) wild cluster approach produce similar results.
} 
with probability 0.875 . In the experiment, we find that the winner of battle 1 wins the overall contest with probability 0.83 , and this qualitative result persist through all 20 periods of the experiment, as evident in Figure 3. It is important to note that a best of three coin-toss model would also generate a probability of 0.75 that the winner of battle 1 wins the overall contest. However, both a binomial test of proportions and a conservative non-parametric test indicate that the observed probability of winning is significantly higher than the prediction from the coin-toss model (0.83 versus 0.75 ; test of proportions, $\mathrm{p}$-value $<0.01$; Wilcoxon signed-rank test, $\mathrm{p}$-value $=$ 0.02, $n=6$ ). Thus, consistent with the New Hampshire Effect, we find that the winner of the battle 1 is more likely to win the overall contest.

Another prediction emerging from the New Hampshire Effect entails that winning battle 1 creates asymmetry, leading the winner of battle 1 to spend more in battle 2 than the loser of battle 1. More specifically, for our parameters, theory predicts that the winner of battle 1 should spend 14.1 in battle 2 and the loser of battle 1 should spend 4.7 in battle 2 (see Table 1 ). Consistent with this prediction, we find that the average expenditure in battle 2 by battle 1 winner is significantly higher than the average expenditure in battle 2 by battle 1 loser (27.0 versus 19.7; Wilcoxon ranksum test, $\mathrm{p}$-value $\left.=0.02, \mathrm{n}_{1}=6, \mathrm{n}_{2}=6\right) .{ }^{18}$

Finding 2: In the sequential contest, the winner of battle 1 wins battle 2 and the overall contest more often than the loser of battle 1 (evidence for Hypothesis 2).

Although we find significant support for the New Hampshire Effect, we also find important deviations from the theory. First, relative to the theoretical benchmarks, we find over-expenditure in all battles. The expenditure in battle 1 is significantly higher than predicted (22.1 versus 16.4;

\footnotetext{
${ }^{18}$ A mixed-effects panel regression collaborates the results of the non-parametric statistical tests (see Table B3 in Appendix B). In estimating this regression, we used a battle 2 expenditure as the dependent variable and a dummyvariable for winning battle 1 , a period trend, and a constant as the independent variables. A regression based on Cameron et al. (2008) wild cluster approach produces similar results.
} 
Wilcoxon signed-rank test, $\mathrm{p}$-value $=0.02, \mathrm{n}=6$ ). The same is true for the expenditure in battle 2 by battle 1 winner (27.0 versus 14.1 ; Wilcoxon signed-rank test, $\mathrm{p}$-value $=0.02, \mathrm{n}=6$ ), the expenditure in battle 2 by battle 1 loser (19.7 versus 4.7; Wilcoxon signed-rank test, $\mathrm{p}$-value = 0.02, $\mathrm{n}=6$ ), and the expenditure in battle 3 (29.6 versus 25.0; Wilcoxon signed-rank test, p-value $=0.04, \mathrm{n}=6) \cdot{ }^{19}$ Our observation of over-expenditure in all three battles is inconsistent with the theoretical predictions of the model, but it can explain why the sequential contests generate much a higher total expenditure than the simultaneous contests (Finding 1).

Second, contrary to the predictions, expenditure in battle 2 is greater than in battle 1 . Specifically, the theory predicts that the expenditure of battle 1 winner should decrease from 16.4 in battle 1 to 14.1 in battle 2 . Instead, the data show that battle 1 winners do not decrease their battle 2 expenditure (25.1 versus 27.0; Wilcoxon signed-rank test, p-value $=0.24, n=6$ ), with 84\% of expenditure in battle 2 being higher than the equilibrium prediction of 14.1, as shown in Figure 4. Similarly, contrary to the predicted decrease in expenditure from 16.4 in battle 1 to 4.7 in battle 2, battle 1 losers also do not decrease their battle 2 expenditure (19.1 versus 19.7; Wilcoxon signed-rank test, $\mathrm{p}$-value $=0.91, \mathrm{n}=6$ ), with $81 \%$ of expenditure in battle 2 being higher than the equilibrium prediction of 4.7, as shown in Figure 4.

Finally, aggressive play by both players explains why the sequential contest lasts longer than expected. Contrary to the theoretical prediction that the sequential contest should end in battle 2 with probability 0.75 , we find that on average the contest ends in battle 2 with probability $0.65 .{ }^{20}$ However, there is some evidence of learning since the likelihood of battle 2 being the decisive one is increasing with the repetition of the experiment (see Figure 3). For example, in the first half of

\footnotetext{
${ }_{19}$ The non-parametric statistical tests are also corroborated by mixed-effect panel regressions (see Table B4 in Appendix B). Regressions based on Cameron et al. (2008) wild cluster approach produce similar results.

${ }^{20}$ See Table B4 in Appendix B.
} 
the experiment $60 \%$ of the contests conclude after two battles, and this proportion increased to $68 \%$ in the second half.

Finding 3: In the sequential contest, over-expenditure is observed in all three battles. Contrary to the theoretical prediction, both battle 1 winner and battle 1 loser do not decrease their expenditure in battle 2 relative to battle 1 . As a result, the probability of contest ending in two battles is lower than predicted.

Significant over-expenditure is consistent with previous findings of contest experiments (Dechenaux et al., 2015; Sheremeta, 2017) and various explanations have been offered in the literature (Sheremeta, 2013, 2015). ${ }^{21}$ We will focus on two explanations: sunk cost and utility of winning. These factors are naturally linked to the multi-stage sequential contests and can explain the observed over-expenditure in these contests; but in addition they also offer an insight into the difference across sequential and simultaneous contests.

\subsubsection{Sunk Cost Fallacy}

The payoff maximization problem underlying the multi-battle sequential contest equilibrium regards the expenditure in previous battles as sunk cost, and therefore ignores them. However, the sequential nature of the contest can create an irrational regard for sunk cost, or in other words, subjects can fall prey to the sunk cost fallacy (Staw, 1976). Evidence from various behavioral studies find that cognitive dissonance can induce people who have sunk resources into an unprofitable activity to irrationally revise their beliefs about the profitability of an additional expenditure, in order to avoid the unpleasant acknowledgment that they made a mistake (Friedman

\footnotetext{
${ }^{21}$ Explanations for over-expenditure in single-battle contests include non-monetary utility of winning (Sheremeta, 2010a, 2010b; Cason et al., 2011, 2012), mistakes (Sheremeta, 2011), misperception of probabilities (Shupp et al., 2013; Chowdhury et al., 2014), evolutionary bias (Mago et al., 2016), and impulsivity (Sheremeta, 2016).
} 
et al., 2007; Baliga and Ely, 2011; Just and Wansink, 2011; Augenblick, 2016). In our experiment, subjects who get to battle 2 have already made some expenditure in battle 1 . If the sunk cost hypothesis is true, it should entail that subjects who spend more resources in battle 1 are also more likely to spend more in battle 2 - to increase their chance of winning the prize and recoup some of their expenditure. Indeed, we find a positive and significant relationship between the expenditure in battle 2 and battle 1 (p-value $<0.01$ ). ${ }^{22}$ However, this positive relationship also could arise because of the presence of a subset or "type" of subjects who tend to spend more in all battles of the sequential contest. Therefore, to provide direct empirical evidence for the sunk cost hypothesis in our experimental environment, we collected additional data from a modified version of the sequential contest.

We ran 5 sessions of a modified version of the sequential contest at Chapman University. The 60 subjects who participated in these additional sessions faced rules that were essentially the same as in the original sequential contest, with the only difference that the subjects did not make any expenditure in battle 1 and the winner of that battle was determined randomly by a computer. This feature allows us to see how subjects behave in battle 2 without prior sunk cost expenditure. Our hypothesis is that if subjects fall prey to sunk cost fallacy then expenditure in the latter battles of the modified contests would be less than in the original sequential contest. Indeed, we find strong support for our hypothesis (and thereby, the sunk cost explanation). In battle 2, expenditure in the modified sequential contest is $25 \%$ lower than in the original sequential contest (18.7 versus 23.3; Wilcoxon rank-sum test, $\mathrm{p}$-value $=0.06, \mathrm{n}_{1}=5, \mathrm{n}_{2}=6$ ). This is also true when we separate our sample by battle 1 winner (22.1 versus 27.0; Wilcoxon rank-sum test, p-value $=0.06, \mathrm{n}_{1}=5$, $\mathrm{n}_{2}=6$ ) and battle 1 loser (15.2 versus 19.7; Wilcoxon rank-sum test, $\mathrm{p}$-value $=0.04, \mathrm{n}_{1}=5, \mathrm{n}_{2}=$

\footnotetext{
22 This conclusion comes from estimating a mixed-effect panel regression.
} 
6). ${ }^{23}$ However, relative to the theoretical predictions, the expenditure in battle 2 is still significantly

higher for battle 1 winner (22.1 versus 14.1; Wilcoxon signed-rank test, $\mathrm{p}$-value $=0.04, \mathrm{n}=5$ ) and for battle 1 loser (15.2 versus 4.7; Wilcoxon signed-rank test, $\mathrm{p}$-value $=0.04, \mathrm{n}=5$ ).

Extending this sunk cost argument to battle 3, it follows that since subjects make lower expenditure in battle 2 we should also observe lower expenditure in battle 3 of the modified sequential contest. In support of this hypothesis, we find that battle 3 expenditure in the modified sequential contest is $36 \%$ lower than in the original sequential contest (21.5 versus 29.7; Wilcoxon rank-sum test, $\mathrm{p}$-value $=0.01, \mathrm{n}_{1}=5, \mathrm{n}_{2}=6$ ). ${ }^{24}$ Moreover, in the modified sequential contest, the expenditure in battle 3 is not statistically different from the theoretical predictions (21.5 versus 25.0; Wilcoxon signed-rank test, $\mathrm{p}$-value $=0.13, \mathrm{n}=5$ ).

Therefore, we find direct empirical evidence supporting the sunk cost explanation for significant over-expenditure in the sequential multi-battle contest. This irrational regard for sunk cost can also explain why the sequential contests generate higher total expenditure than the simultaneous contests (Finding 1). Although the number of battles is identical in both simultaneous and sequential contest, the temporal sequencing of the sequential contest results in a sunk cost fallacy while this effect is absent in the simultaneous contest.

\subsubsection{Utility of Winning}

Cox et al. (1988) were among the first to suggest the utility of winning as an explanation for overbidding in auctions, and Goeree et al. (2002) used an empirical strategy to identify the

\footnotetext{
${ }^{23}$ The non-parametric statistical tests are also collaborated by mixed-effect panel regressions (see Table B5 in Appendix B). In estimating these regressions, we used a battle 2 expenditure as the dependent variable and a treatment dummy-variable, a period trend, and a constant as the independent variables. Regressions based on Cameron et al. (2008) wild cluster approach produce similar results.

24 See Table B5 in Appendix B.
} 
utility of winning. In a contest framework, Sheremeta (2010b) proposed a method of directly measuring the utility of winning in an incentive compatible way. Since then, numerous experimental studies have employed non-monetary utility of winning as an explanation for overexpenditure in contests (Sheremeta, 2013, 2015; Cason et al., 2011, 2012; Price and Sheremeta, 2011, 2015; Mago et al., 2016).

We employ the non-monetary utility of winning to explain some patterns in our data that cannot be explained by the sunk cost fallacy. Specifically, in the sequential contest, we find that the reduced probability of the contest ending in battle 2 and the resulting over-expenditure is largely driven by the increased expenditure in battle 2, by both battle 1 winner and battle 1 loser (Finding 3). Since this increased expenditure is not grounded in standard equilibrium explanation and may not be completely accounted for by the sunk cost fallacy, we postulate that subjects may derive additional non-monetary utility from winning itself. ${ }^{25}$

Based on the assumption that subjects care only about their monetary prize, standard equilibrium theory predicts that battle 1 loser will suffer from a dramatic decrease in his continuation value for the next battle, and accordingly spend less in battle 2; given this, the winner of battle 1 will also reduce his expenditure in battle 2 . However, if we incorporate winning as a component in the subject's utility function, the decline in continuation value is not so dramatic for either players. Following similar theoretical models presented in Parco et al. (2005), Amaldoss and Rapoport (2009), and Sheremeta (2010b, 2013), suppose the non-monetary utility takes an additive form, i.e., in addition to the value of the prize $v$, individuals also have a non-monetary

\footnotetext{
${ }^{25}$ As evidenced in the prior discussion, sunk cost fallacy cannot explain all the deviations from the theory. Even in the modified sessions, expenditure in battle 2 remains significantly higher relative to the theoretical predictions for both winner and loser of battle 1 . Also, the sunk cost fallacy cannot explain the fact that battle 1 loser (who presumably spent less resources in battle 1 , and should not be subject to sunk cost fallacy as much as battle 1 winner) does not give up in battle 2 .
} 
utility of winning $w$, where $0 \leq w \leq v$. Then instead of (3), the updated expected payoff in battle 3 becomes:

$$
E^{\prime}\left(\pi_{X 3}\right)=\frac{x_{3}}{x_{3}+y_{3}}(v+w)-x_{3}
$$

Similarly, instead of (4), the updated expected payoffs in battle 2 become:

$$
E^{\prime}\left(\pi_{X 2}\right)=\frac{x_{2}}{x_{2}+y_{2}}(v+w)+\frac{y_{2}}{x_{2}+y_{2}} E^{\prime *}\left(\pi_{3}\right)-x_{2} \text { and } E^{\prime}\left(\pi_{Y 2}\right)=\frac{y_{2}}{x_{2}+y_{2}}\left(E^{\prime *}\left(\pi_{3}\right)+w\right)-y_{2}
$$

Finally, instead of (5), the updated payoff in battle 1 becomes:

$$
E^{\prime}\left(\pi_{X 1}\right)=\frac{x_{1}}{x_{1}+y_{1}}\left(E^{\prime *}\left(\pi_{X 2}\right)+w\right)+\frac{y_{1}}{x_{1}+y_{1}} E^{\prime *}\left(\pi_{Y 2}\right)-x_{1} .
$$

Although we cannot obtain a closed form solution analytically, we can solve this model numerically. Figure 5 shows expenditures in the sequential contest in all three battles as a function of the utility of winning $w$, for $w \in[0,100]$. It is clear that the utility of winning gives incentive to both players to engage in higher spending. Specifically, upon accounting for $w$, both winner and loser of battle 1 make higher than predicted expenditures in battle 2 for $w \in(0,100]$; and despite this over-dissipation, the expenditure in battle 2 by battle 1 winner is higher than by battle 1 loser for $w \in[0,100)$. This predicted pattern of expenditure is consistent with our Finding 2.

Furthermore, the utility of winning provides an equilibrium explanation for why the loser of battle 1 does not decrease his/her expenditure in battle 2 as much as predicted (Finding 3). From Figure 5 it is evident that as $w$ increases, the gap in expenditure in battle 2 by winner and loser of battle 1, and the corresponding New Hampshire Effect, decreases. In fact, when utility of winning is equal to prize of the contest $(v=w=100)$ the equilibrium expenditure of the winner is same as that of the loser.

Utility of winning may also provide insight into why expenditure is significantly higher in sequential contests compared to simultaneous contests (Finding 1). Both Parco et al. (2005) and Sheremeta (2010b) suggest that the utility of winning is increasing in the number of stages. 
Although the number of battles is identical in both simultaneous and sequential contest, in the sequential contest subjects can receive non-monetary utility of winning up to two times (when each battle winner is announced) while in the simultaneous contest such utility is received only once (when the overall winner is announced). Figure 6 shows total expenditure in sequential and simultaneous contests as a function of the utility of winning $w$, for $w \in[0,100]$. It is evident that the sequential contest generates higher total expenditure than the simultaneous contest for $w \in$ $[15,100]$ (i.e., higher than $15 \%$ of the prize value $v=100$ ). The lower bound for $w$ is fairly conservative, given the results of Sheremeta (2010a, 2010b) and Price and Sheremeta (2010, 2015), where $w$ is estimated to be around $50 \%$ of the prize value.

\subsection{Simultaneous Contests}

For the simultaneous contest, theory predicts that subjects allocate expenditure equally across all the three battles (Hypothesis 3). Our data reveals that although the average expenditure in all three battles is close to the predicted level of 12.5 (Table 2), none of the subjects who participated in the simultaneous contest employ a uniform expenditure strategy. Most subjects vary their expenditure between battles, with the difference from the mean expenditure across all three battles averaging at a steep 12.1. Figure 7 displays the average difference from the mean expenditure across all three battles in a given period. A lower magnitude of dispersion implies a more uniform expenditure strategy and obviously, in equilibrium, the magnitude of dispersion should be zero. We find that although there is some evidence that the dispersion of expenditure across the three battles decreases in the first five periods of the experiment; on the whole, the average difference in expenditure between battles remains positive and significant over the entire length of the experiment. 
Figure 8 displays the distribution of expenditure within each battle over all 20 periods of the simultaneous contest. Two things stand out. First, despite the large variance, the overall distribution of expenditure is remarkably similar in the three battles indicating no preferential bias between battles. ${ }^{26}$ Second, subjects' expenditures are distributed over the entire strategy space, which is clearly inconsistent with play at a unique pure strategy Nash equilibrium. While a large majority of the expenditure is centered close to the equilibrium prediction of 12.5 , there is also substantial variation in expenditure.

Finding 4: Subjects in the simultaneous contest do not employ a uniform expenditure strategy. There is substantial dispersion in expenditure both between-battles in a given period and within-battles over time.

This dispersion in expenditure (both between and within battles) alludes to a strategy akin to "guerilla warfare.” To win the overall contest, a player needs to win a minimum of two battles. She does not derive any additional utility from winning all three battles. This suggests that players can randomly select and focus their expenditure on just two battles. We find that the average minimum expenditure in a battle is 7.7 , almost half the prediction of 12.5 . Indeed, $24 \%$ of time, expenditure in one of the battles is less than or equal to 1 . Similarly, expenditure in the remaining two battles averages at 16.3 , and exceeds the equilibrium prediction more $62 \%$ of the time. Although contrary to the theoretical prediction, focusing on the minimal set of battles which are sufficient for victory has an intuitive appeal and such behavior has been observed in other multibattle contest experiments (see the review by Sheremeta, 2017). ${ }^{27}$

\footnotetext{
${ }^{26}$ That is, there is no allocation bias such as that observed in Colonel Blotto games (Chowdhury et al., 2013), where players who read and write from left to right horizontally in their native language tend to allocate greater expenditure to the battles on the left.

${ }^{27}$ It is important to emphasize, however, that the "guerilla warfare" strategy is not an equilibrium strategy. In fact, in the context of a lottery contest success function, the only equilibrium is to allocate resources uniformly across all battles (Klumpp and Polborn, 2006; Kovenock et al., 2010; Kovenock and Roberson, 2012).
} 


\section{Conclusion}

In this study we use a laboratory experiment to compare sequential and simultaneous contests, where candidates have to win the majority of battles in order to obtain a prize. Candidates influence the probability of winning a battle by their choice of expenditure in that battle. We find that, contrary to prediction, sequential contests generate significantly higher expenditure than simultaneous contests. This is mainly because in sequential contests, there is significant overexpenditure in all three battles. We suggest sunk cost fallacy and utility of winning as two complementary explanations for this behavior and provide supporting evidence.

Our findings have implications both for policy makers and social scientists. In particular, the finding that sequential contests induce higher expenditure (and thus more inefficiency) than simultaneous contests is both interesting and puzzling. Previous theoretical and empirical research on sequential and simultaneous voting provides mixed evidence in favor of sequential system (Morton and Williams, 1999, 2000; Klumpp and Polborn, 2006). Battaglini et al. (2007), for example, find that a sequential voting rule is more efficient but less equitable than simultaneous voting in some information environments. We show that, on the contrary, simultaneous contest dominates sequential contest because it generates substantially lower expenditure. Thus, we provide evidence that attempts such as 'Frontloading' and 'Super Tuesday' to make presidential nomination process more like the simultaneous contest may indeed lead to a more efficient and significantly less costly electoral process. Furthermore, our result that sunk costs result in higher expenditure in the sequential costs may have important implications for the organizational structure of the primaries. The choice of New Hampshire, which represent 0.4 percent of the U.S. population, as the first primary state may be an attempt to keep the overall campaign costs as small 
as possible. Similarly, utility of winning may be one of the explanations why candidates with later finishes continue to seek the nomination.

Our theoretical construct is a prototype model of a strategic multi-dimensional resource allocation game (Kovenock and Roberson, 2012). Although our experimental design is built around the theoretical model of Klumpp and Polborn (2006), who compare sequential and simultaneous multi-battle contests in the context of primary elections, our design can also be used to analyze problems in various fields such as military and systems defense (Hausken, 2008), advertising resource allocation (Friedman, 1958), and research and development portfolio selection (Clark and Konrad, 2008).

Our experimental design considers the simplest setting of two symmetric players in a threebattle contest. While our experimental framework captures some of the most salient features of sequential and simultaneous contests, we have set aside empirically relevant issues, such as candidate strength differences, state-specific advantages, and endogenous donations, which limits the external validity of our results. Extending our design to account for these issues remains a promising avenue for future research. For instance, given the observed deviations from predictions, it would be interesting to study how behavior evolves in case of more battles and/or asymmetric players. 


\section{References}

Altmann, S., Falk, A. \& Wibral, M. (2012). Promotions and incentives: The case of multistage elimination tournaments. Journal of Labor Economics, 30, 149-174.

Amegashie, J.A., Cadsby, C.B., \& Song, Y. (2007). Competitive burnout: Theory and experimental evidence. Games and Economic Behavior, 59, 213-239.

Arad, A. \& Rubinstein, A. (2012). Multi-dimensional iterative reasoning in action: The case of the Colonel Blotto game. Journal of Economic Behavior and Organization, 84, 571-585.

Arad, A. (2012). The Tennis Coach problem: A game-theoretic and experimental study. The B.E. Journal of Theoretical Economics, 12, 10.

Augenblick, N. (2016). The sunk-cost fallacy in penny auctions. Review of Economic Studies, 83, 58-86.

Avrahami, J., \& Kareev, Y. (2009). Do the weak stand a chance? Distribution of resources in a competitive environment. Cognitive Science, 33, 940-950.

Baik, K. \& Lee, S. (2000).Two-stage rent-seeking contests with carryovers. Public Choice, 103, 285-296.

Baliga, S., \& Ely, J.C. (2011). Mnemonomics: The sunk cost fallacy as a memory kludge. American Economic Journal: Microeconomics, 3, 35-67.

Battaglini, M., Morton, R.B., \& Palfrey, T.R. (2007). Efficiency, equity and timing of voting mechanisms. American Political Science Review, 101, 409-424.

Borel, E. (1921). La theorie du jeu les equations integrales a noyau symetrique. Comptes Rendus del Academie. 173, 1304-1308; English translation by Savage, L. (1953). The theory of play and integral equations with skew symmetric kernels. Econometrica, 21, 97-100.

Busch, A., \& Mayer, W. (2004). The front-loading problem. In: Mayer, W. (Eds.), The making of the presidential candidate. Rowman and Littlefied Publishers, Inc, USA, 83-132.

Callander, S. (2007). Bandwagons and momentum in sequential voting. Review of Economic Studies, 74, 653-684

Cameron, A.C., Gelbach, J.B., \& Miller, D.L. (2008). Bootstrap-based improvements for inference with clustered errors. Review of Economics and Statistics, 90, 414-427.

Cason, T.N., Masters, W.A. \& Sheremeta, R.M. (2011). Winner-take-all and proportional-prize contests: Theory and experimental results. Working Paper.

Cason, T.N., Sheremeta, R.M., \& Zhang, J. (2012). Communication and efficiency in competitive coordination games. Games and Economic Behavior, 76, 26-43.

Chowdhury, S.M., Kovenock, D. \& Sheremeta, R.M. (2013). An experimental investigation of Colonel Blotto games. Economic Theory, 52, 833-861.

Chowdhury, S.M., Sheremeta, R.M., Turocy, T.L. (2014). Overbidding and overspreading in rentseeking experiments: Cost structure and prize allocation rules. Games and Economic Behavior. 87, 224-238.

Clark, D.J., \& Konrad, K.A. (2007). Asymmetric conflict weakest link against best shot. Journal of Conflict Resolution, 51, 457-469.

Clark, D.J., \& Konrad, K.A. (2008). Fragmented property rights and incentives for R\&D. Management Science, 54, 969-981.

Cox, J.C., Smith, V.L., \& Walker, J.M. (1988). Theory and individual behavior of first-price auctions. Journal of Risk and Uncertainty, 1, 61-99.

Davis, D., \& Reilly, R. (1998). Do too many cooks spoil the stew? An experimental Analysis of rent-seeking and the role of a strategic buyer. Public Choice, 95, 89-115. 
Dechenaux, E., Kovenock, D. \& Sheremeta, R.M. (2015). A Survey of experimental research on contests, all-pay auctions and tournaments. Experimental Economics, 18, 609-669.

Deck, C. \& Sheremeta, R.M. (2012). Fight or flight? Defending against sequential attacks in the Game of Siege. Journal of Conflict Resolution, 56, 1069-1088.

Deck, C. \& Sheremeta, R.M. (2016). Tug-of-war in the laboratory. Working Paper.

Duffy, J., \& Matros, A. (2015). Stochastic asymmetric Blotto games: Some new results. Economics Letters, 134, 4-8.

Feigenbaum, J.J., \& Shelton, C.A. (2013). The vicious cycle: Fundraising and perceived viability in US presidential primaries. Quarterly Journal of Political Science, 8, 1-40.

Fischbacher, U. (2007). z-Tree: Zurich toolbox for ready-made economic experiments. Experimental Economics, 10, 171-178.

Friedman, D., Pommerenke, K., Lukose, R., Milam, G. \& Huberman, B. (2007) Searching for the sunk cost fallacy. Experimental Economics, 10, 79-104.

Friedman, L. (1958). Game-theory models in the allocation of advertising expenditure. Operations Research, 6, 699-709.

Fudenberg, D., Gilbert, R., Stiglitz, J., \& Tirole, J. (1983). Preemption, leapfrogging and competition in patent races. European Economic Review, 22, 3-31.

Gelder, A., \& Kovenock, D. (2017). Dynamic behavior and player types in majoritarian multibattle contests. Games and Economic Behavior, 104, 444-455.

Goeree, J.K., Holt, C.A., \& Palfrey, T.R. (2002). Quantal response equilibrium and overbidding in private-value auctions. Journal of Economic Theory, 104, 247-272.

Harris, C., \& Vickers, J. (1985). Perfect equilibrium in a model of a race. Review of Economic Studies, 52, 193-209.

Harris, C., \& Vickers, J. (1987). Racing with uncertainty. Review of Economic Studies, 54, 1-21.

Hausken, K. (2008). Strategic defense and attack for series and parallel reliability systems. European Journal of Operational Research, 186, 856-881.

Höchtl, W., Kerschbamer, R., Stracke, R. \& Sunde, U. (2015). Incentives vs. selection in promotion tournaments: Can a designer kill two birds with one stone? Managerial and Decision Economics, 36, 275-285.

Holt, C.A. \& Laury, S.K. (2002). Risk aversion and incentive effects. American Economic Review, 92, 1644-1655.

Holt, C.A., Kydd, A., Razzolini, L., \& Sheremeta, R. (2016). The paradox of misaligned profiling theory and experimental evidence. Journal of Conflict Resolution, 60, 482-500.

Hortala-Vallve, R. \& Llorente-Saguer, A. (2010). A simple mechanism for resolving conflict. Games and Economic Behavior, 70, 375-391.

Just, D.R., \& Wansink, B. (2011). The flat-rate pricing paradox: Conflicting effects of "all-youcan-eat” buffet pricing. Review of Economics and Statistics, 93, 193-200.

Klumpp, T., \& Polborn, M.K. (2006). Primaries and the New Hampshire effect. Journal of Public Economics, 90, 1073-1114.

Konrad, K.A., \& Kovenock, D. (2009). Multi-battle contests. Games Economic Behavior, 66, 256274.

Kovenock, D. \& Roberson, B (2012). Conflicts with multiple battlefields. In Garfinkel, M.R., Skaperdas, S. (Eds.), Oxford Handbook of the Economics of Peace and Conflict. New York: Oxford University Press, pp. 503-531.

Kovenock, D., Roberson, B. \& Sheremeta, R.M. (2010). The attack and defense of weakest-link networks. Working Paper. 
Kvasov, D. (2007). Contests with limited resources. Journal of Economic Theory, 136, 738-748.

Leininger, W. (1991). Patent competition, rent dissipation, and the persistence of monopoly: the role of research budgets. Journal of Economic Theory, 53, 146-172.

Mago, S.D. \& Sheremeta, R.M. (2017). Multi-battle contests: An experimental study. Southern Economic Journal, forthcoming.

Mago, S.D., Savikhin, A.C. \& Sheremeta, R.M. (2015). Facing your opponents: Social identification and information feedback in contests. Journal of Conflict Resolution, 60, 459481.

Mago, S.D., Sheremeta, R.M. \& Yates, A. (2013). Best-of-three contest experiments: Strategic versus psychological momentum. International Journal of Industrial Organization, 31, 287296.

Mayer, W. (2004). The basic dynamics of contemporary nomination process. In: Mayer, W. (Eds.), The making of the presidential candidate. Rowman and Littlefied Publishers, Inc, USA, 83132.

McKee, M. (1989). Intra-experimental income effects and risk aversion. Economic Letters, 30, 109-115.

Montero, M., Possajennikov, A., Sefton, M., \& Turocy, T.L. (2016). Majoritarian Blotto contests with asymmetric battlefields: An experiment on Apex games. Economic Theory, 61, 55-89.

Morton, R.B., \& Williams, K.C. (1999). Information asymmetries and simultaneous versus sequential voting. American Political Science Review, 93, 51-67.

Morton, R.B., \& Williams, K.C. (2000). Learning by voting: Sequential choices in presidential primaries and other elections. Ann Arbor, MI: University of Michigan Press.

Parco J., Rapoport A., \& Amaldoss W. (2005). Two-stage contests with budget constraints: An experimental study. Journal of Mathematical Psychology, 49, 320-338.

Price, C.R. \& Sheremeta, R.M. (2011). Endowment effects in contests. Economics Letters, 111, 217-219.

Price, C.R. \& Sheremeta, R.M. (2015). Endowment origin, demographic effects and individual preferences in contests. Journal of Economics and Management Strategy, 24, 597-619.

Roberson, B. (2006). The Colonel Blotto game. Economic Theory, 29, 1-24.

Ryvkin, D. (2011). Fatigue in dynamic tournaments. Journal of Economics and Management Strategy, 20, 1011-1041.

Schmitt, P., Shupp, R. Swope, K., \& Cadigan, J. (2004). Multi-period rent-seeking contests with carryover: Theory and experimental evidence. Economics of Governance, 10, 247-259.

Sheremeta, R.M. (2010a). Expenditures and information disclosure in two-stage political contests. Journal of Conflict Resolution, 54, 771-798.

Sheremeta, R.M. (2010b). Experimental comparison of multi-stage and one-stage contests. Games and Economic Behavior, 68, 731-747.

Sheremeta, R.M. (2011). Contest design: An experimental investigation. Economic Inquiry, 49, 573-590.

Sheremeta, R.M. (2013). Overbidding and heterogeneous behavior in contest experiments. Journal of Economic Surveys, 27, 491-514.

Sheremeta, R.M. (2015). Behavioral dimensions of contests. In Congleton, R.D., Hillman, A.L., (Eds.), Companion to the Political Economy of Rent Seeking, London: Edward Elgar, pp. 150164.

Sheremeta, R.M. (2016). Impulsive behavior in competition: Testing theories of overbidding in rent-seeking contests. Working Paper. 
Sheremeta, R.M. (2017). Experimental research on contests. Working Paper.

Sheremeta, R.M., \& Zhang, J. (2010). Can groups solve the problem of over-bidding in contests? Social Choice and Welfare, 35, 175-197.

Shupp, R., Sheremeta, R.M., Schmidt, D., \& Walker, J. (2013). Resource allocation contests: Experimental evidence. Journal of Economic Psychology, 39, 257-267.

Snyder, J. (1989). Election goals and the allocation of campaign resources. Econometrica, 57, 630660.

Staw, B.M. (1976). Knee-deep in the big muddy: A study of escalating commitment to a chosen course of action. Organizational Behavior and Human Performance, 16, 27-44.

Szentes, B., \& Rosenthal, R.W. (2003). Beyond chopsticks: Symmetric equilibria in majority auction games. Games and Economic Behavior, 45, 278-295.

Tullock, G. (1980). Efficient rent seeking. In James M. Buchanan, Robert D. Tollison, Gordon Tullock, (Eds.), Toward a theory of the rent-seeking society. College Station, TX: Texas A\&M University Press, pp. 97-112.

Zizzo, D.J. (2002). Racing with uncertainty: A patent race experiment. International Journal of Industrial Organization, 20, 877-902. 
Table 1: Equilibrium Predictions in Sequential and Simultaneous Contests

\begin{tabular}{l|c|c}
\hline \hline Treatments & Sequential & Simultaneous \\
\hline Final prize, $v$ & 100 & 100 \\
Number of battles, $n$ & 3 & 3 \\
\hline & Equilibrium & Equilibrium \\
\hline Expenditure in battle 1 & 16.4 & 12.5 \\
Expenditure in battle 2 by battle 1 winner & 14.1 & 12.5 \\
Expenditure in battle 2 by battle 1 loser & 4.7 & - \\
Expenditure in battle 3 & 25.0 & 12.5 \\
Probability of contest ending in battle 2 & 0.75 & - \\
Expected total expenditure & 32.0 & 37.5 \\
Expected payoff & 18.0 & 12.5 \\
\hline
\end{tabular}

Table 2: Average Statistics

\begin{tabular}{|c|c|c|c|c|}
\hline \multirow{3}{*}{$\begin{array}{l}\text { Treatments } \\
\text { Final prize, } v \\
\text { Number of battles, } n\end{array}$} & \multicolumn{2}{|c|}{ Sequential } & \multicolumn{2}{|c|}{ Simultaneous } \\
\hline & \multicolumn{2}{|c|}{100} & \multicolumn{2}{|c|}{$\begin{array}{c}100 \\
3\end{array}$} \\
\hline & Equilibrium & Actual & Equilibrium & Actual \\
\hline Expenditure in battle 1 & 16.4 & $22.1(13.4)$ & 12.5 & $13.3(10.2)$ \\
\hline Expenditure in battle 2 by battle 1 winner & 14.1 & $27.0(14.8)$ & 12.5 & $13.8(9.9)$ \\
\hline Expenditure in battle 2 by battle 1 loser & 4.7 & $19.7(15.9)$ & - & - \\
\hline Expenditure in battle 3 by battle 2 winner & 25.0 & $29.6(15.9)$ & 12.5 & $13.2(10.1)$ \\
\hline Expenditure in battle 3 by battle 2 loser & 25.0 & $29.7(16.1)$ & - & - \\
\hline Probability of contest ending in battle 2 & 0.75 & $0.64(0.47)$ & - & - \\
\hline Average total expenditure & 32.0 & $56.0(33.3)$ & 37.5 & $40.3(23.9)$ \\
\hline Average payoff & 18.0 & $-6.0(53.1)$ & 12.5 & $9.6(49.5)$ \\
\hline
\end{tabular}

Standard deviation in parentheses. 
Figure 1: Average Expenditure over 20 Periods in the Sequential Contest

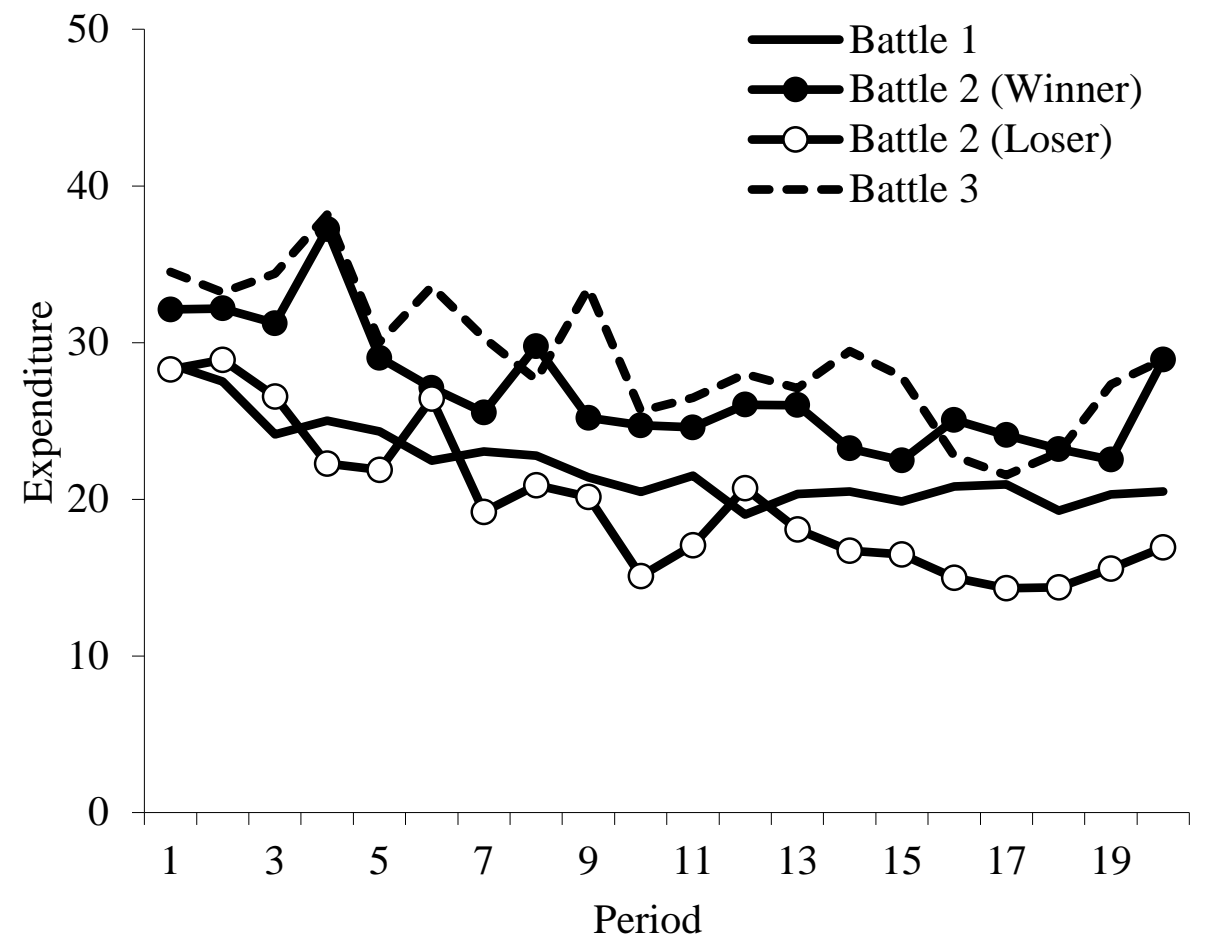

Figure 2: Average Expenditure over 20 Periods in the Simultaneous Contest

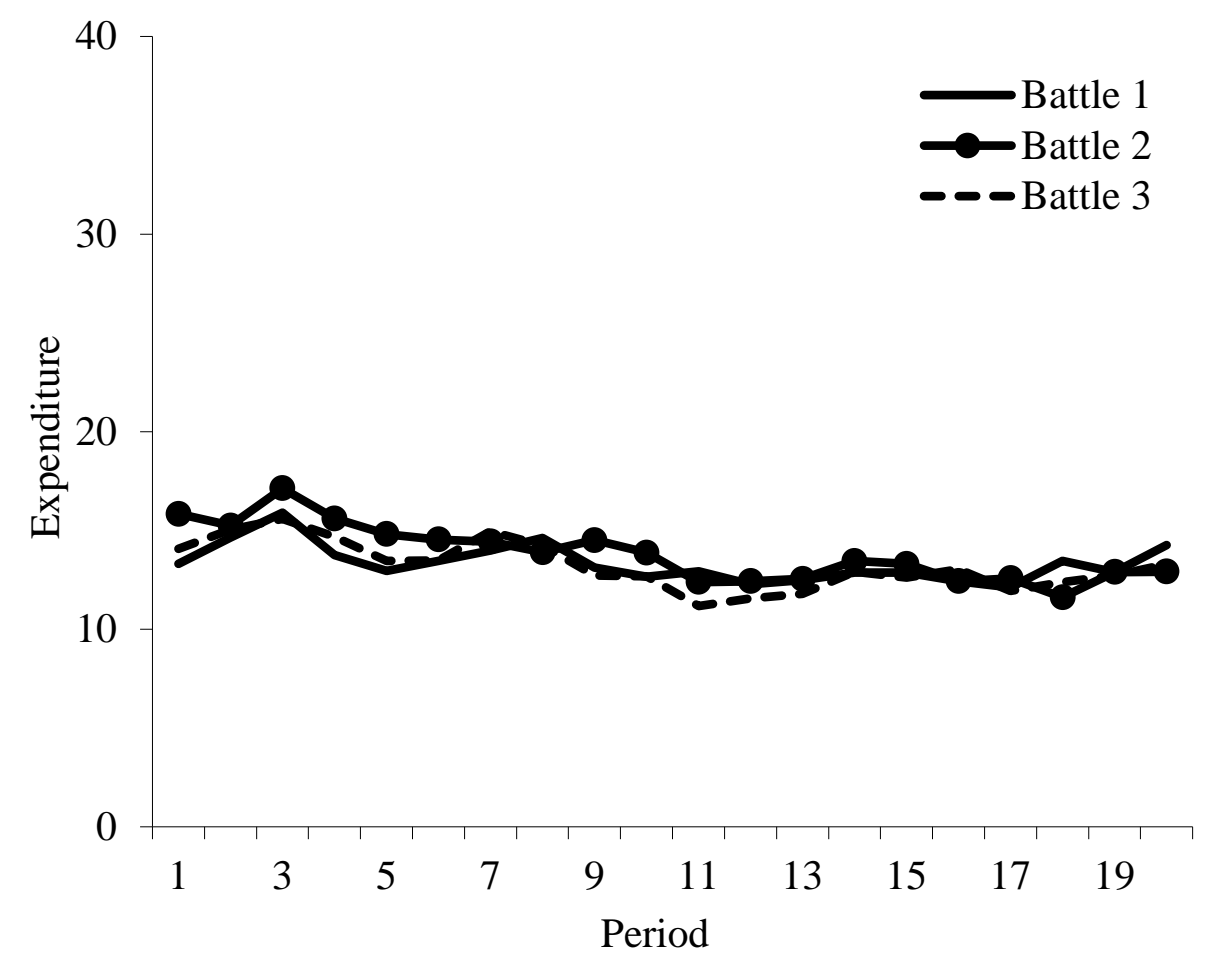


Figure 3: Probability of Ending and Winning the Sequential Contest

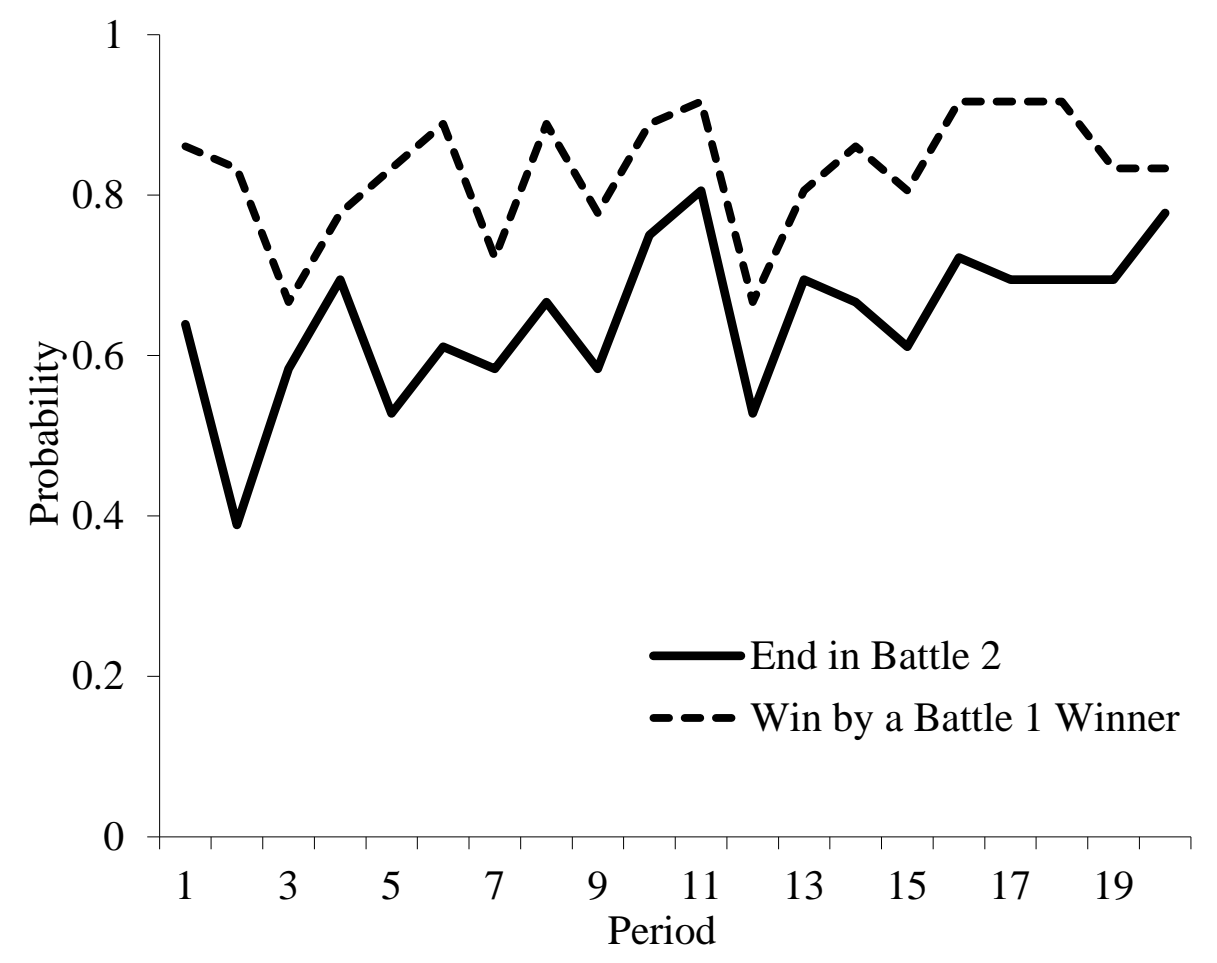

Figure 4: Distribution of Expenditure in the Sequential Contest

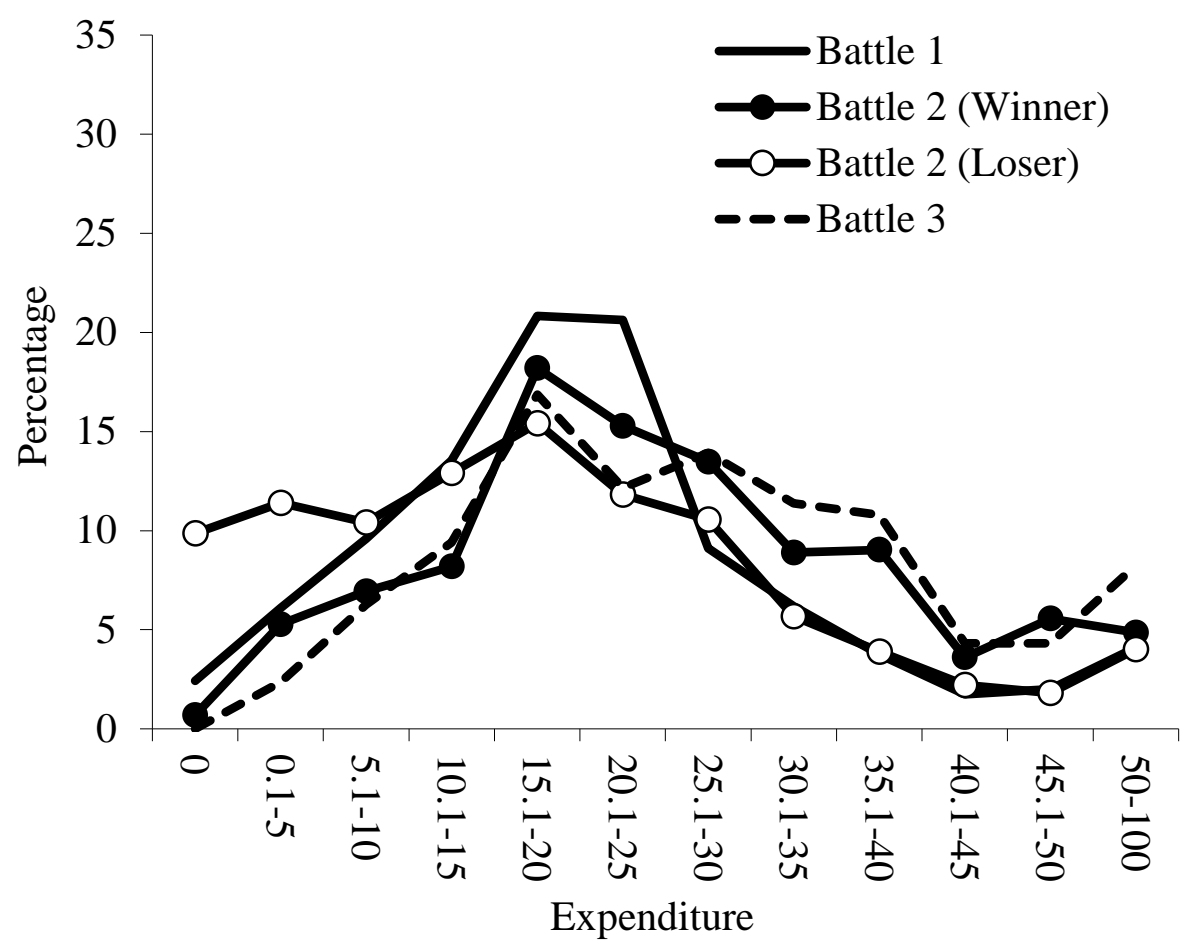


Figure 5: Expenditure in the Sequential Contest as a Function of the Utility of Winning

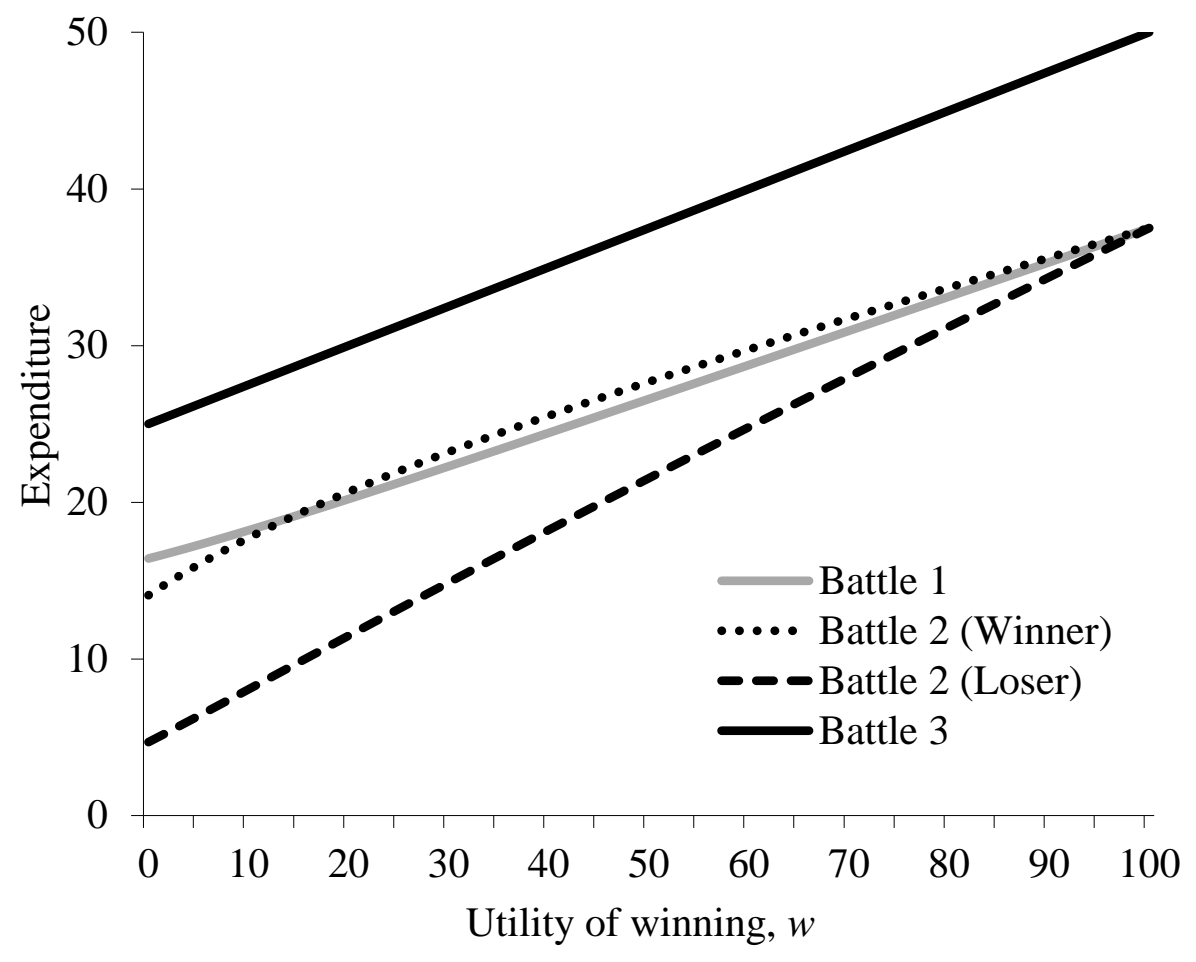

Figure 6: Total Expenditure in Sequential and Simultaneous Contests as a Function of the

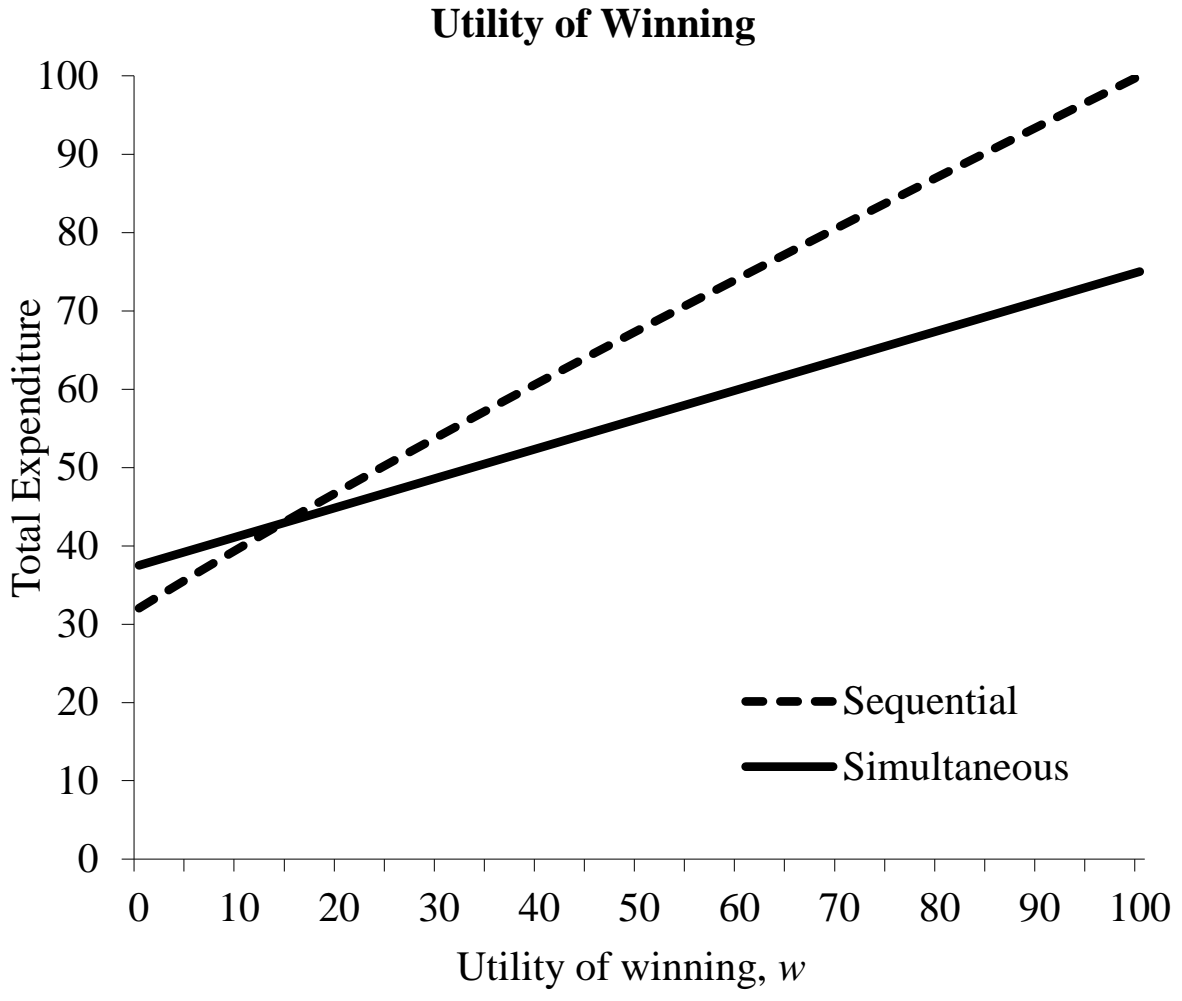


Figure 7: Average Difference from the Mean Expenditure across Three Battles in the

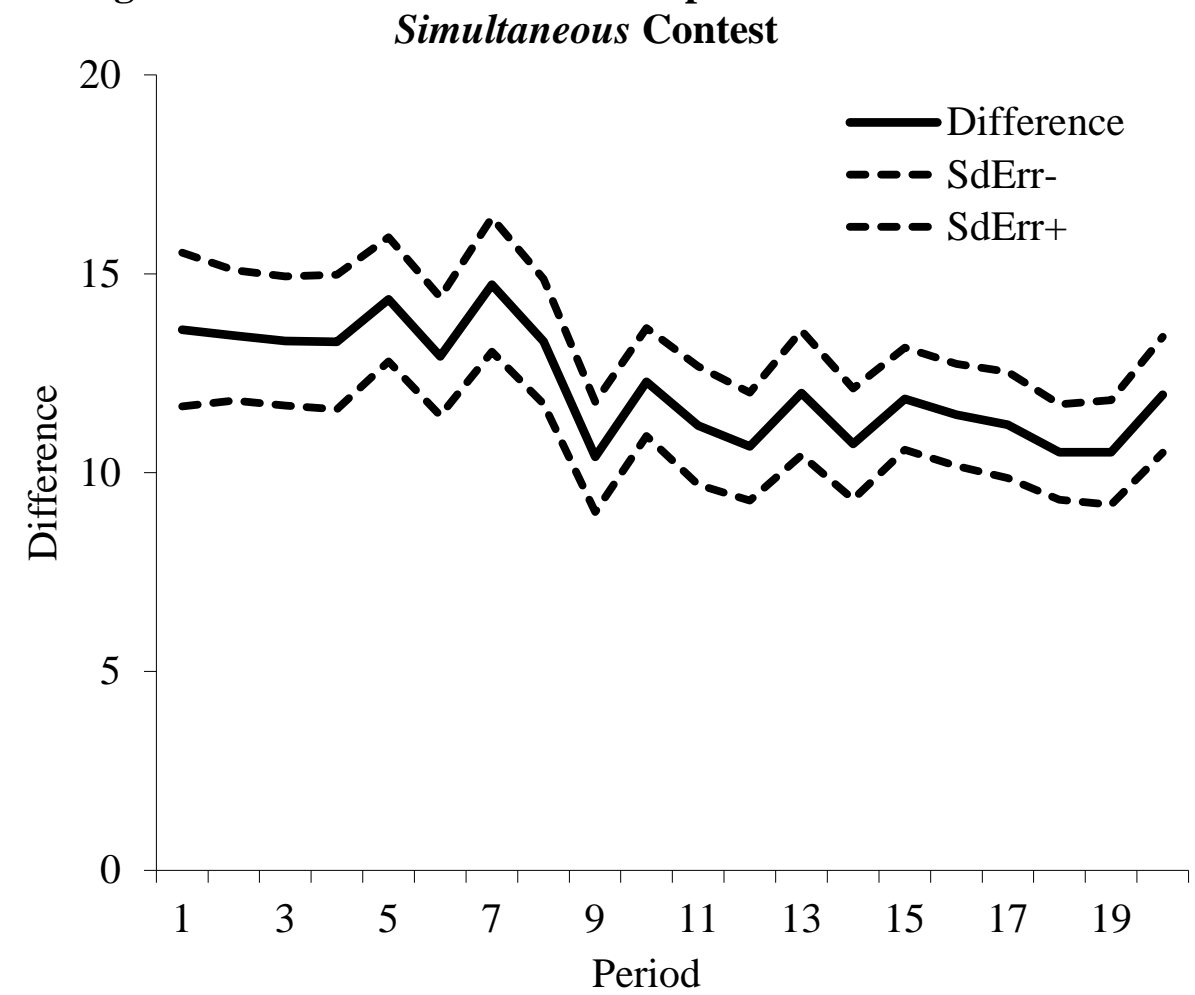

Figure 8: Distribution of Expenditure in the Simultaneous Contest

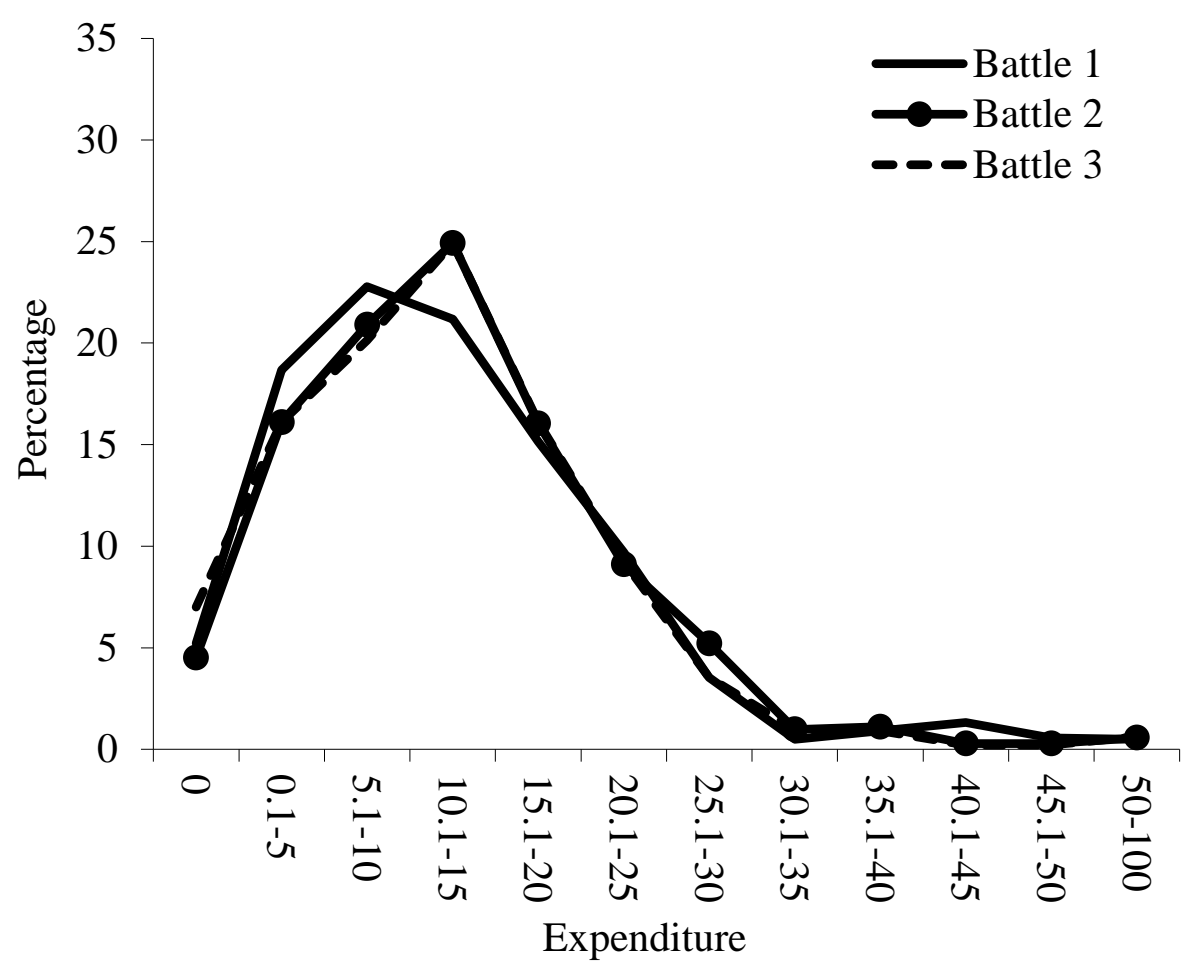




\section{Appendix A (For Online Publication): Instructions}

\section{GENERAL INSTRUCTIONS}

This is an experiment in the economics of strategic decision making. Various research agencies have provided funds for this research. The instructions are simple. If you follow them closely and make appropriate decisions, you can earn an appreciable amount of money.

The experiment will proceed in two parts. Each part contains decision problems that require you to make a series of economic choices which determine your total earnings. The currency used in part 1 of the experiment is U.S. Dollars. The currency used in part 2 of the experiment is francs. These francs will be converted to U.S. Dollars at a rate of $\_25$ francs to $\_\mathbf{1}$ dollar. You have already received a $\mathbf{\$ 2 0 . 0 0}$ participation fee (this includes your show-up fee of \$7.00). Your earnings from both part 1 and part 2 of the experiment will be incorporated into your participation fee. At the end of today's experiment, you will be paid in private and in cash. There are $\mathbf{1 2}$ participants in today's experiment.

It is very important that you remain silent and do not look at other people's work. If you have any questions, or need assistance of any kind, please raise your hand and an experimenter will come to you. If you talk, laugh, exclaim out loud, etc., you will be asked to leave and you will not be paid. We expect and appreciate your cooperation.

\section{INSTRUCTIONS FOR PART 1}

In this part of the experiment you will be asked to make a series of choices in decision problems. How much you receive will depend partly on chance and partly on the choices you make. The decision problems are not designed to test you. What we want to know is what choices you would make in them. The only right answer is what you really would choose.

For each line in the table in the next page, please state whether you prefer option A or option B. Notice that there are a total of $\mathbf{1 5}$ lines in the table but only one line will be randomly selected for payment. Each line is equally likely to be selected, and you do not know which line will be selected when you make your choices. Hence you should pay attention to the choice you make in every line. After you have completed all your choices a token will be randomly drawn out of a bingo cage containing tokens numbered from 1 to 15. The token number determines which line is going to be selected for payment.

Your earnings for the selected line depend on which option you chose: If you chose option A in that line, you will receive \$1. If you chose option B in that line, you will receive either $\mathbf{\$ 3}$ or $\mathbf{\$ 0}$. To determine your earnings in the case you chose option B there will be second random draw. A token will be randomly drawn out of the bingo cage now containing twenty tokens numbered from $\mathbf{1}$ to 20. The token number is then compared with the numbers in the line selected (see the table). If the token number shows up in the left column you earn $\$ 3$. If the token number shows up in the right column you earn $\$ 0$.

While you have all the information in the table, we ask you that you input all your 15 decisions into the computer. The actual earnings for this part will be determined at the end of part 2, and will be independent of part 2 earnings.

\begin{tabular}{|c|c|c|c|c|}
\hline $\begin{array}{l}\text { Decisi } \\
\text { on no. }\end{array}$ & Option A & & $\begin{array}{c}\text { Option } \\
\mathrm{B}\end{array}$ & $\begin{array}{c}\text { Please choose } \\
\text { A or B }\end{array}$ \\
\hline 1 & $\$ 1$ & \$3 never & $\mathbf{\$ 0}$ if $1,2,3,4,5,6,7,8,9,10,11,12,13,14,15,16,17,18,19,20$ & \\
\hline 2 & $\$ 1$ & $\$ 3$ if 1 comes out of the bingo cage & \$0 if 2,3,4,5,6,7,8,9,10,11,12,13,14,15,16,17,18,19,20 & \\
\hline 3 & $\$ 1$ & $\$ 3$ if 1 or 2 & \$0 if 3,4,5,6,7,8,9,10,11,12,13,14,15,16,17,18,19,20 & \\
\hline 4 & $\$ 1$ & $\$ 3$ if $1,2,3$ & $\mathbf{\$ 0}$ if $4,5,6,7,8,9,10,11,12,13,14,15,16,17,18,19,20$ & \\
\hline 5 & $\$ 1$ & $\$ 3$ if $1,2,3,4$, & $\$ 0$ if $5,6,7,8,9,10,11,12,13,14,15,16,17,18,19,20$ & \\
\hline 6 & $\$ 1$ & $\$ 3$ if $1,2,3,4,5$ & $\$ \mathbf{~} \mathbf{0}$ if $6,7,8,9,10,11,12,13,14,15,16,17,18,19,20$ & \\
\hline 7 & $\$ 1$ & $\$ 3$ if $1,2,3,4,5,6$ & $\$ 0$ if $7,8,9,10,11,12,13,14,15,16,17,18,19,20$ & \\
\hline 8 & $\$ 1$ & $\$ 3$ if $1,2,3,4,5,6,7$ & \$0 if 8,9,10,11,12,13,14,15,16,17,18,19,20 & \\
\hline 9 & $\$ 1$ & $\$ 3$ if $1,2,3,4,5,6,7,8$ & $\$ 0$ if $9,10,11,12,13,14,15,16,17,18,19,20$ & \\
\hline 10 & $\$ 1$ & $\$ 3$ if $1,2,3,4,5,6,7,8,9$ & $\$ 0$ if $10,11,12,13,14,15,16,17,18,19,20$ & \\
\hline 11 & $\$ 1$ & $\$ 3$ if $1,2,3,4,5,6,7,8,9,10$ & \$0 if $11,12,13,14,15,16,17,18,19,20$ & \\
\hline 12 & $\$ 1$ & $\$ 3$ if $1,2,3,4,5,6,7,8,9,10,11$ & $\$ 0$ if $12,13,14,15,16,17,18,19,20$ & \\
\hline 13 & $\$ 1$ & $\$ 3$ if $1,2,3,4,5,6,7,8,9,10,11,12$ & $\$ 0$ if $13,14,15,16,17,18,19,20$ & \\
\hline 14 & $\$ 1$ & $\$ 3$ if $1,2,3,4,5,6,7,8,9,10,11,12,13$ & $\$ 0$ if $14,15,16,17,18,19,20$ & \\
\hline 15 & $\$ 1$ & $\$ 3$ if 1,2 & $\$ 0$ if $15,16,17,18,19,20$ & \\
\hline
\end{tabular}




\section{Instructions for the Simultaneous Treatment}

\section{INSTRUCTIONS FOR PART 2 YOUR DECISION}

The second part of the experiment consists of $\mathbf{2 0}$ decision-making periods. The 12 participants in today's experiment will be randomly re-matched every period into 6 groups with 2 participants in each group. Therefore, the specific person who is the other participant in your group will change randomly after each period. The group assignment is anonymous, so you will not be told which of the participants in this room are assigned to your group

Each period you and the other participant in your group will simultaneously make bids (any number, including 0.1 decimal points) in three boxes. Your bid in each box cannot exceed 100 francs. The more you bid, the more likely you are to win a particular box. This will be explained in more detail later. The participant who wins at least two boxes receives the reward of $\mathbf{1 0 0}$ francs. Your total earnings depend on whether you receive the reward or not and how many francs you spent on bidding. An example of your decision screen is shown below:

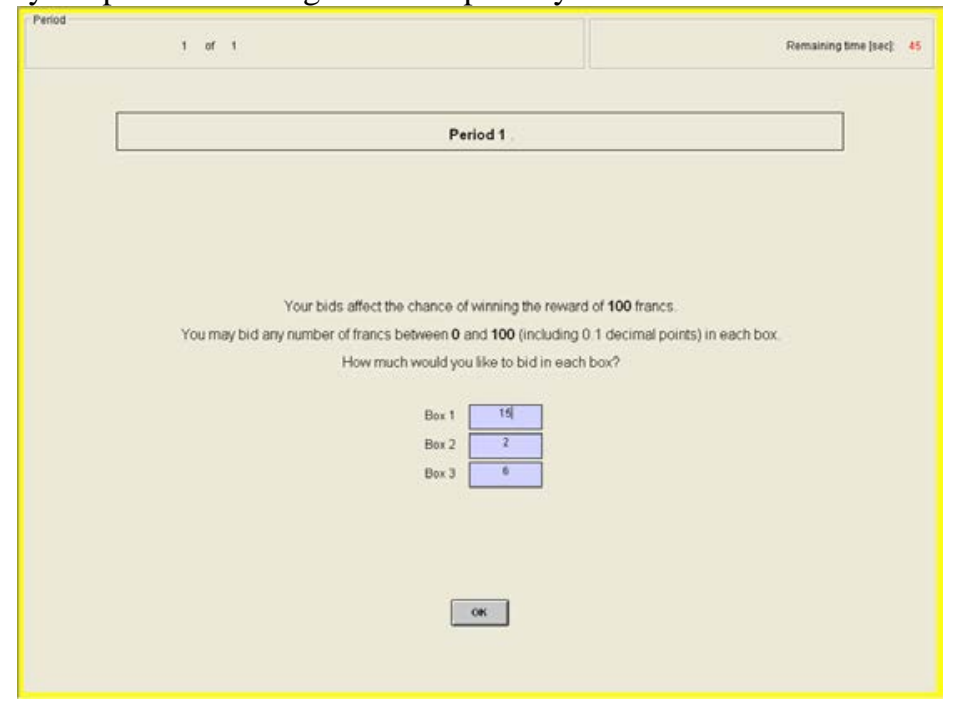

\section{CHANCE OF WINNING A BOX}

The more you bid in a particular box, the more likely you are to win that box. The more the other participant bids in the same box, the less likely you are to win that box. Specifically, for each franc you bid in a particular box you will receive one lottery ticket. At the end of each period the computer draws randomly one ticket among all the tickets purchased by you and the other participant in the group. The owner of the drawn ticket wins. Thus, your chance of winning a particular box is given by the number of francs you bid in that box divided by the number of francs you and the other participant bid in that box.

Your chance of Your Bid in That Box

winning a box $\quad=\quad$ Your Bid in That Box + The Other Participant's Bid in That Box

In case both participants bid zero in the same box, the computer determines randomly who wins that box.

Example: This is an example to illustrate how the computer makes a random draw of lottery tickets. Suppose, participant 1 bids 10 francs in box 1 and participant 2 bids 20 francs in box 1 . Therefore, the computer assigns 10 lottery tickets to participant 1 and 20 lottery tickets to participant 2 . Then the computer randomly draws one lottery ticket out of 30 tickets $(10+20=30)$. As you can see, participant 2 has higher chance, $\mathbf{0 . 6 7}=\mathbf{2 0} / \mathbf{3 0}$, while participant 1 has lower chance, $\mathbf{0 . 3 3}=\mathbf{1 0 / 3 0}$, of winning box 1 .

In the sheet attached to these instructions, you will find a probability table. This table will give you some idea of how your bid and the other participant's bid affect your chance of winning. For instance, suppose you bid 50 francs and the other participant bid 30 francs then your chance of winning the box is 0.63 . Note that as stated before, your chance of winning increases as your bid increases relative to the other participant's bid. So if you bid 70 francs and the other participant is still bidding 30 francs, your chance of winning increases to 0.70 . To assist you with calculation of more precise numbers, we will provide you with the Excel calculator. You may use the calculator to find the chance of winning for any combination of your bid and the other participant's bid. We will have a few practice rounds with the Excel calculator before the start of the experiment. 


\section{YOUR EARNINGS}

Your earnings depend on whether you receive the reward or not and how many francs you spent on bidding. The participant who wins at least two boxes receives the reward of $\mathbf{1 0 0}$ francs. Regardless of who receives the reward, both participants will have to pay their bids in each box. Thus, the period earnings will be calculated in the following way:

Earnings of the participant who won at least two boxes= 100 - (bid in box 1) - (bid in box 2) - (bid in box 3)

Earnings of the participant who won less than two boxes $=0$ - (bid in box 1) - (bid in box 2) - (bid in box 3 )

\section{END OF THE PERIOD}

After both participants make their box bids, the computer will make a random draw for each box separately and independently. The random draws made by the computer will decide which boxes you win. The computer will calculate your period earnings based on whether you received the reward or not and how many francs you spent on bidding in each box. Both participants will observe the outcome of the period - your bid in each box, other participant's bids in each box, winner of each box, and your earnings from that period, as shown below. Once the outcome screen is displayed you should record your results for the period on your Personal Record Sheet under the appropriate heading. You will be randomly re-matched with a different participant at the start of the next period.

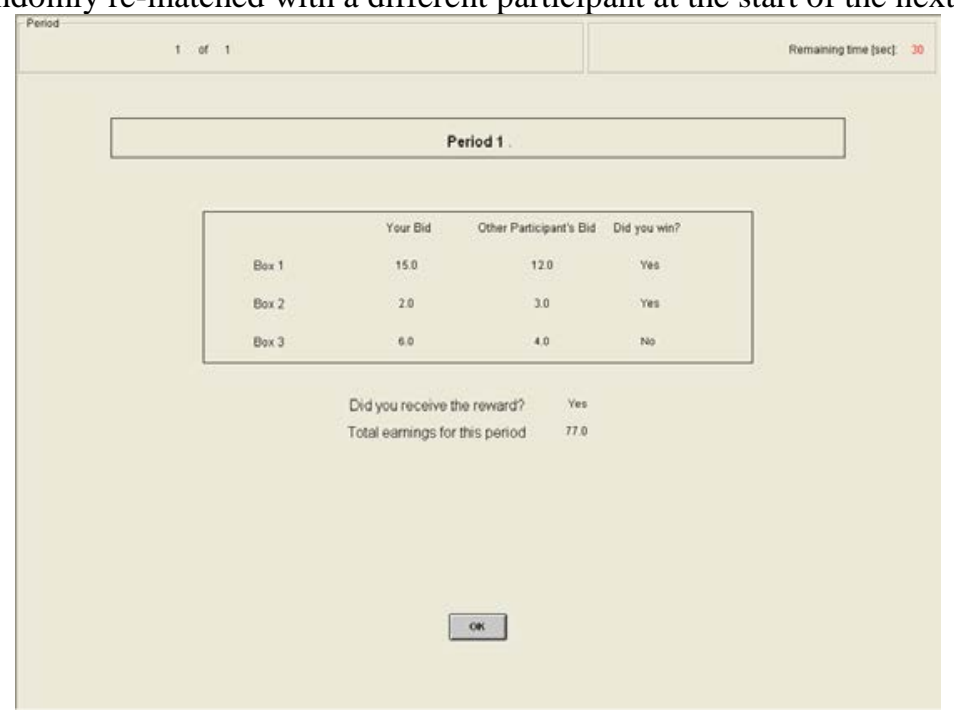

\section{END OF THE EXPERIMENT}

At the end of the experiment we will use the bingo cage to randomly select 2 out of 20 periods for actual payment. Depending on the outcome in a given period, you may receive either positive or negative earnings. You will sum the total earnings for these 2 periods and convert them to a U.S. dollar payment, as shown on the last page of your personal record sheet. Remember you have already received a $\mathbf{\$ 2 0 . 0 0}$ participation fee (equivalent to $\mathbf{5 0 0}$ francs). If your earnings from this part of the experiment are positive, we will add them to your participation fee. If your earnings are negative, we will subtract them from your participation fee.

\section{Instructions for the Sequential Treatment}

\section{INSTRUCTIONS FOR PART 2 YOUR DECISION}

The second part of the experiment consists of $\mathbf{2 0}$ decision-making periods. The 12 participants in today's experiment will be randomly re-matched every period into 6 groups with 2 participants in each group. Therefore, the specific person who is the other participant in your group will change randomly after each period. The group assignment is anonymous, so you will not be told which of the participants in this room are assigned to your group

Each period consists of a maximum of three rounds. The period ends when one of the participants wins two of the three rounds ("best of three"). Thus, each period will consist of either two or three rounds. In each round, you and the other participant in your group will simultaneously make a bid (any number, including 0.1 decimal points). Your bid in each round cannot exceed 100 francs. The more you bid, the more likely you are to win a particular round. This will be explained in more detail later. The participant who is first to win two rounds receives the reward of 100 
francs. Your earnings depend on whether you receive the reward or not and how many francs you spent on bidding. An example of your decision screen is shown below:

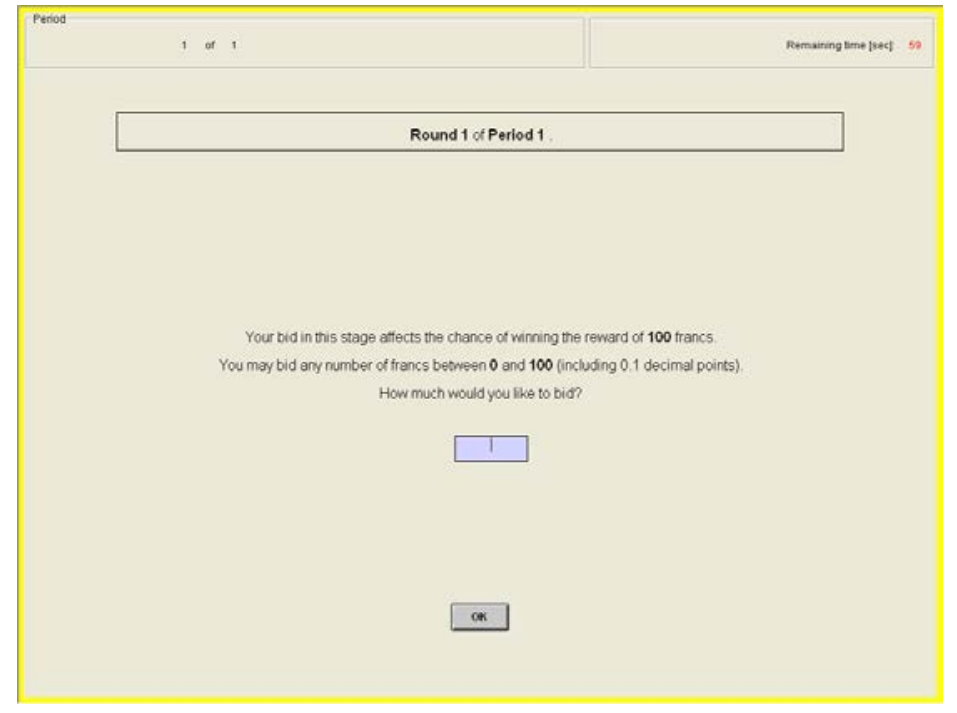

\section{CHANCE OF WINNING A ROUND}

The more you bid in a particular round, the more likely you are to win that round. The more the other participant bids in the same round, the less likely you are to win that round. Specifically, for each franc you bid you will receive one lottery ticket. At the end of each round the computer draws randomly one ticket among all the tickets purchased by you and the other participant in the group. The owner of the drawn ticket wins. Thus, your chance of winning a round is given by the number of francs you bid in that round divided by the number of francs you and the other participant bid in that round.

Your chance of

$$
=\quad \text { Your Bid in That Round }
$$

winning a round

$=$

Your Bid in That Round + The Other Participant's Bid in That Round

In case both participants bid zero, the computer determines randomly who wins that round.

Example: This is an example to illustrate how the computer makes a random draw of lottery tickets. Suppose, in a given round participant 1 bids 10 francs and participant 2 bids 20 francs. Therefore, the computer assigns 10 lottery tickets to participant 1 and 20 lottery tickets to participant 2 . Then the computer randomly draws one lottery ticket out of 30 tickets $(10+20=30)$. As you can see, participant 2 has higher chance, $\mathbf{0 . 6 7}=\mathbf{2 0} / \mathbf{3 0}$, while participant 1 has lower chance, $\mathbf{0 . 3 3}=\mathbf{1 0 / 3 0}$, of winning the round.

In the sheet attached to these instructions, you will find a probability table. This table will give you some idea of how your bid and the other participant's bid affect your chance of winning. For instance, suppose you bid 50 francs and the other participant bid 30 francs then your chance of winning the round is 0.63 . Note that as stated before, your chance of winning increases as your bid increases relative to the other participant's bid. So if you bid 70 francs and the other participant is still bidding 30 francs, your chance of winning increases to 0.70 . To assist you with calculation of more precise numbers, we will provide you with the Excel calculator. You may use the calculator to find the chance of winning for any combination of your bid and the other participant's bid. We will have a few practice rounds with the Excel calculator before the start of the experiment.

\section{YOUR EARNINGS}

Your earnings depend on whether you receive the reward or not and how many francs you spent on bidding in each round. The participant who is first to win two rounds receives the reward of $\mathbf{1 0 0}$ francs. Regardless of who receives the reward, both participants will have to pay their bids in each round. One of the four payment scenarios is possible:

(1) If the period lasted for only two rounds

(1a) Earnings of the participant who won both rounds are $=100-($ bid in round 1) - (bid in round 2)

(1b) Earnings of the participant who won neither rounds are $=0$ - (bid in round 1) - (bid in round 2)

(2) If the period lasted for three rounds

(2a) Earnings of the participant who won two rounds are $=100-$ (bid in round 1) - (bid in round 2) - (bid in round)

(2b) Earnings of the participant who won one round are $=0$ - (bid in round 1) - (bid in round 2) - (bid in round 3) 


\section{END OF THE ROUND}

After both participants make their round bids, the computer will make a random draw which will determine the winner of the round. Both participants will observe the outcome of the round - your bid, other participant's bid and winner, as shown below. Then they make bids in another round. This continues until one of the participants in the group wins two rounds.

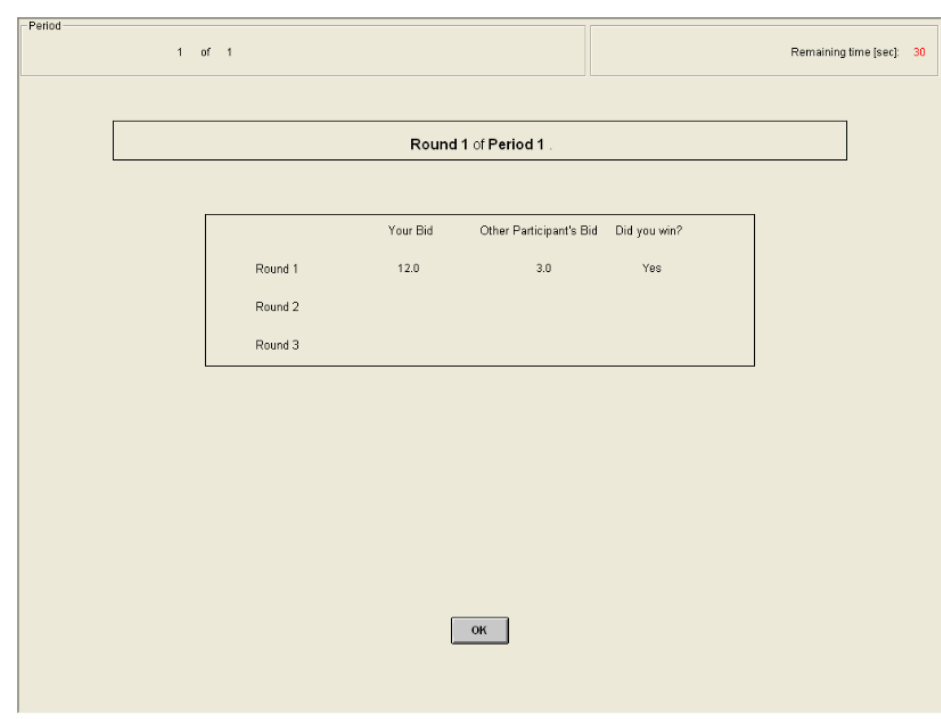

\section{END OF THE PERIOD}

The period ends when one of the participants in the group wins two rounds. At the end of the period, the computer will calculate your period earnings based on the number of rounds you won and how many francs you spent on bidding in each round. Your earnings from that period will be reported on the outcome screen as shown below. Once the outcome screen is displayed you should record your results for the period on your Personal Record Sheet under the appropriate heading. You will be randomly re-matched with a different participant at the start of the next period.

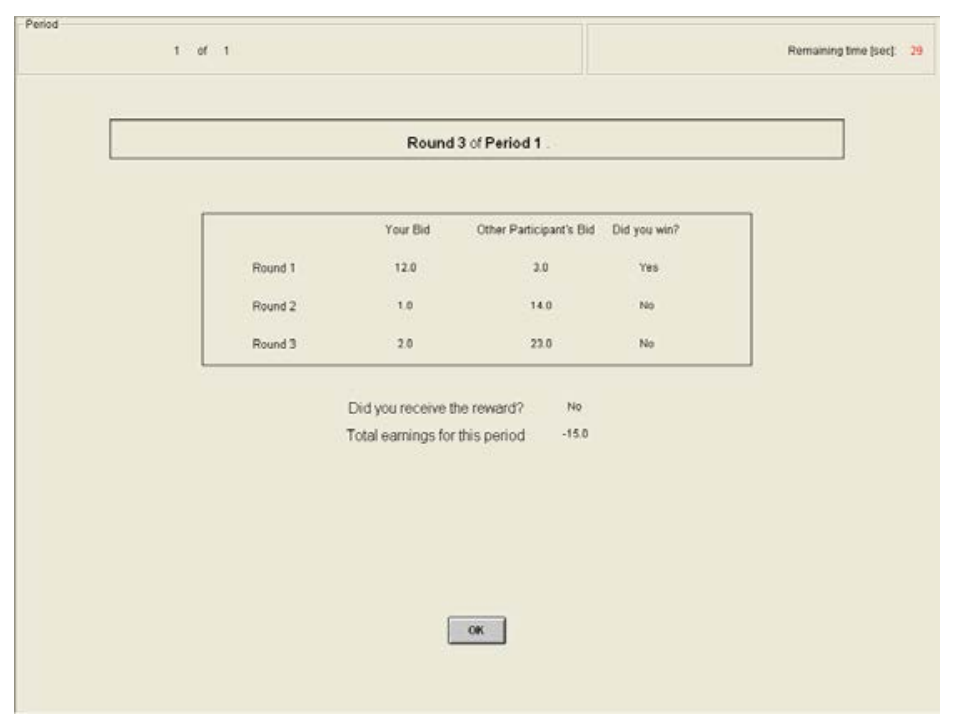

\section{END OF THE EXPERIMENT}

At the end of the experiment we will use the bingo cage to randomly select 2 out of 20 periods for actual payment. Depending on the outcome in a given period, you may receive either positive or negative earnings. You will sum the total earnings for these 2 periods and convert them to a U.S. dollar payment, as shown on the last page of your personal record sheet. Remember you have already received a $\mathbf{\$ 2 0 . 0 0}$ participation fee (equivalent to $\mathbf{5 0 0}$ francs). If your earnings from this part of the experiment are positive, we will add them to your participation fee. If your earnings are negative, we will subtract them from your participation fee. 


\section{Appendix B (For Online Publication): Additional Tables}

Table B1: Mixed-Effects Panel Models (Theory)

\begin{tabular}{lcc}
\hline \hline Treatment & Sequential & Simultaneous \\
\hline Dependent variable & Total expenditure & Total expenditure \\
\hline Period & $32.33^{* * *}$ & $8.34^{* * *}$ \\
[inverse period trend] & $(3.09)$ & $(2.32)$ \\
Constant & $50.21^{* * *}$ & $38.88^{* * *}$ \\
& $(3.35)$ & $(2.70)$ \\
\hline Observations & 1,440 & 1,440 \\
\hline Hypothesis & Constant $=32.0$ & Constant $=37.5$ \\
p-value & $<0.01$ & $=0.60$ \\
\hline * significant at $10 \%, * *$ & significant at 5\%, $* * *$ significant at $1 \%$. The \\
standard errors are in parentheses. All models include a mixed-effects & \\
error structure to account for session and individual subject effects.
\end{tabular}

Table B2: Mixed-Effects Panel Models (Finding 1)

\begin{tabular}{lcc}
\hline \hline Treatment & $\begin{array}{c}\text { Sequential and } \\
\text { Simultaneous }\end{array}$ & $\begin{array}{c}\text { Sequential and } \\
\text { Simultaneous }\end{array}$ \\
\hline Period & $1-20$ & $11-20$ \\
\hline Dependent variable & Total expenditure & Total expenditure \\
\hline Sequential & $15.64^{* * *}$ & $11.22^{* *}$ \\
$\quad[1$ if sequential contest] & $(4.25)$ & $(4.54)$ \\
Period & $20.33^{* * *}$ & 19.97 \\
$\quad[$ inverse period trend] & $(1.94)$ & $(31.52)$ \\
Constant & $36.72^{* * *}$ & $36.52 * * *$ \\
& $(3.03)$ & $(3.84)$ \\
\hline Observations & 2,880 & 1,440 \\
\hline Hypothesis & Sequential $=0$ & Sequential $=0$ \\
p-value & $<0.01$ & $=0.02$ \\
\hline * significant at $10 \%, * *$ significant at $5 \%, * * *$ significant at $1 \%$. The standard \\
errors are in parentheses. All models include a mixed-effects error structure \\
to account for session and individual subject effects.
\end{tabular}


Table B3: Mixed-Effects Panel Models (Finding 2)

\begin{tabular}{lc}
\hline \hline Treatment & Sequential \\
\hline Dependent variable & Expenditure in battle 2 \\
\hline Win & $5.16^{* * *}$ \\
[1 if the winner of battle 1] & $(0.70)$ \\
Period & $13.37 * * *$ \\
$\quad$ inverse period trend] & $(1.52)$ \\
Constant & $18.39 * * *$ \\
& $(1.66)$ \\
\hline Observations & 2,880 \\
\hline Hypothesis & Win $=0$ \\
p-value & $<0.01$ \\
\hline * significant at $10 \%, * *$ significant at $5 \%, * * *$ significant at \\
$1 \%$. The standard errors are in parentheses. All models \\
include a mixed-effects error structure to account for session \\
and individual subject effects.
\end{tabular}

Table B4: Mixed-Effects Panel Models (Finding 3)

\begin{tabular}{|c|c|c|c|c|c|}
\hline Treatment & Sequential & Sequential & Sequential & Sequential & Sequential \\
\hline Dependent variable & $\begin{array}{l}\text { Expenditure } \\
\text { in battle } 1\end{array}$ & $\begin{array}{c}\text { Expenditure } \\
\text { in battle } 2 \\
\text { (battle } 1 \text { winner) }\end{array}$ & $\begin{array}{c}\text { Expenditure } \\
\text { in battle } 2 \\
\text { (battle } 1 \text { loser) }\end{array}$ & $\begin{array}{l}\text { Expenditure } \\
\text { in battle } 3\end{array}$ & End in battle 2 \\
\hline $\begin{array}{l}\text { Period } \\
\text { [inverse period trend] }\end{array}$ & $\begin{array}{c}10.30^{* * *} \\
(1.09)\end{array}$ & $\begin{array}{c}10.33^{* * *} \\
(1.98)\end{array}$ & $\begin{array}{c}15.44^{* * *} \\
(1.98)\end{array}$ & $\begin{array}{c}7.32 * * * \\
(2.40)\end{array}$ & $\begin{array}{c}-0.16^{* * *} \\
(0.06)\end{array}$ \\
\hline Constant & $\begin{array}{c}20.29 * * * \\
(1.18)\end{array}$ & $\begin{array}{c}24.46 * * * \\
(1.70)\end{array}$ & $\begin{array}{c}18.22 * * * \\
(2.12)\end{array}$ & $\begin{array}{c}28.51^{* * *} \\
(1.99)\end{array}$ & $\begin{array}{c}0.67^{* * *} \\
(0.03)\end{array}$ \\
\hline Observations & 1440 & 720 & 720 & 510 & \\
\hline $\begin{array}{l}\text { Hypothesis } \\
\text { p-value }\end{array}$ & $\begin{array}{c}\text { Constant }=16.4 \\
<0.01\end{array}$ & $\begin{array}{l}\text { Constant }=14.1 \\
<0.01\end{array}$ & $\begin{array}{c}\text { Constant }=4.7 \\
<0.01\end{array}$ & $\begin{array}{l}\text { Constant }=25.0 \\
\quad=0.07\end{array}$ & $\begin{array}{l}\text { Constant }=0.75 \\
=0.02\end{array}$ \\
\hline
\end{tabular}


Table B5: Mixed-Effects Panel Models (Sunk Cost)

\begin{tabular}{lcccc}
\hline Treatment & Sequential & Sequential & Sequential & Sequential \\
Dependent variable & $\begin{array}{c}\text { Expenditure } \\
\text { in battle 1 }\end{array}$ & $\begin{array}{c}\text { Expenditure } \\
\text { in battle 2 } \\
\text { (battle 1 winner) }\end{array}$ & $\begin{array}{c}\text { Expenditure } \\
\text { in battle 2 } \\
\text { (battle 1 loser) }\end{array}$ & $\begin{array}{c}\text { Expenditure } \\
\text { in battle 3 }\end{array}$ \\
\hline Sunk $\quad-4.66^{* *}$ & $-3.85^{*}$ & $-6.01^{* *}$ & $-8.02^{* * *}$ \\
$\quad$ 1 if sunk treatment] & $(1.92)$ & $(2.32)$ & $(2.38)$ & $(2.65)$ \\
Period & $8.54^{* * *}$ & $5.94^{* * *}$ & $10.83^{* * *}$ & $5.33^{* * *}$ \\
$\quad$ inverse period trend] & $(1.05)$ & $(1.29)$ & $(1.33)$ & $(1.60)$ \\
Constant & $21.84 * * *$ & $25.24 * * *$ & $19.06^{* * *}$ & $28.92^{* * *}$ \\
& $(1.31)$ & $(1.58)$ & $(1.62)$ & $(1.82)$ \\
\hline Observations & 2640 & 1320 & 1320 & 960 \\
\hline Hypothesis & Sunk $=0$ & Sunk $=0$ & Sunk $=0$ & Sunk $=0$ \\
p-value & $=0.02$ & $=0.09$ & $=0.02$ & $<0.01$ \\
\hline * significant at 10\%, ** significant at 5\%, $* * *$ significant at 1\%. The standard errors are in \\
parentheses. All models include a mixed-effects error structure to account for session and \\
individual subject effects.
\end{tabular}

